\title{
Joint Capacity Investment, Collecting and Pricing Decisions in a Capacity Constraint Closed-Loop Supply Chain Considering Cooperation
}

\author{
Jian Wang ${ }^{1,2, *(1)}$ and Wenxuan Shao ${ }^{1,2}$ \\ 1 School of Artificial Intelligence and Automation, Huazhong University of Science and Technology, \\ Wuhan 430074, China; shaowenxuan@hust.edu.cn \\ 2 Key Laboratory of Image Processing and Intelligent Control, Ministry of Education, Wuhan 430074, China \\ * Correspondence: wj0826_can@hust.edu.cn
}

check for updates

Citation: Wang, J.; Shao, W. Joint Capacity Investment, Collecting and Pricing Decisions in a Capacity Constraint Closed-Loop Supply Chain Considering Cooperation. Sustainability 2021, 13, 8725. https: //doi.org/10.3390/su13168725

Academic Editor:Andrea Appolloni

Received: 19 June 2021

Accepted: 2 August 2021

Published: 4 August 2021

Publisher's Note: MDPI stays neutral with regard to jurisdictional claims in published maps and institutional affiliations.

Copyright: (c) 2021 by the authors. Licensee MDPI, Basel, Switzerland. This article is an open access article distributed under the terms and conditions of the Creative Commons Attribution (CC BY) license (https:/ / creativecommons.org/licenses/by/ $4.0 /)$.

\begin{abstract}
In this paper, a closed-loop supply chain (CLSC) consisting of one manufacturer and one supplier is considered. The capacity of the manufacturer is limited, the manufacturer can increase capacity by investing in capacity, and there are different cooperation contracts among the supply chain members. This paper pushes collecting activities upstream, assumes that the collecting activity can be completed by the supplier, and accepts that there is cooperation between the members, which increases supplier involvement. Dynamic game models among CLSC members are formulated. The optimal decisions of pricing, capacity investment, and collecting channels of the CLSC members are obtained, and the impacts of some important factors, for example, the capacity investment cost coefficient and the cost-sharing factors, on optimal decisions are investigated. The results reveal that the supplier collecting mode performs better in some scenarios; therefore, the management enlightenment desired by the supplier can be obtained. Additionally, the coordination between the manufacturer and the supplier sometimes fails to increase the closed-loop supply chain's sustainability, which is a finding quite different from some current research results.
\end{abstract}

Keywords: closed-loop supply chain; dual recycling channel; capacity constraint; capacity investment; coordination

\section{Introduction}

With the accelerated industrialization and urbanization, the contradiction between economic development and resources and environment is becoming more and more prominent, which has become one prominent problem limiting China's sustainable development. Collecting and remanufacturing of recyclable resources is an important means to alleviate this problem. Based on recycling and waste recovery, sustainable consumption and production are also part of the sustainable development goals [1]. Theoretically, collecting and remanufacturing is defined as "a production strategy whose goal is to recover the residual value of old products by reusing components that are still in good working order" [2]. Currently, the collection rate of scrap metal in China is only about $20 \%$, while it is over $50 \%$ in the United States and up to $90 \%$ in Japan. Adding collecting activities to the original forward flow of the supply chain constitutes a closed-loop supply chain (CLSC) system that has been popularly studied in recent years, while the reverse flow brought by the collection and reuse of products to the product supply chain makes full use of resources, which can largely alleviate the problem of resource shortage and contribute to environmental protection efforts. In recent years, domestic research on collecting and remanufacturing has focused on two aspects: collection mode and pricing of remanufactured products. The choice of collection mode and the pricing of remanufactured products affect the development of collection and remanufacturing. In this paper, we will study the corresponding optimal decision from the decision problem concerning the collection channel in the CLSC. 
We divide the research on the existing CLSC decision problem regarding collection channels into two categories, one considering online collecting channels and the other considering only offline collecting channels of members. In the first category, online collecting activities are mostly left to manufacturers directly, while collecting activities in the second category are done offline by supply chain members such as the manufacturer, the retailer, and the third-party collectors, which is more complicated than the first category because it often requires considering the transfer price as an additional decision variable. The existing research literature on the second category of problem is extensive, Lang and Shi [3], Ranjbar et al. [4], Ji et al. [5], Xu et al. [6], etc., which can be subdivided into discussions of different supply chain structures, collecting channels, and coordination contracts according to their research characteristics. In terms of existing studies, most scholars discuss the CLSCs consisting of the manufacturer and the retailer [5-7], or the manufacturer, the retailer, and the third-party collector $[4,8,9]$, and dominated by the manufacturer. In studies on collecting channels, scholars often consider the manufacturer collecting, the retailer collecting, the third-party collector collecting, and dual-channel collecting to arrive at the optimal collecting channel through calculation and analysis. Among the studies related to coordination contracts, cost-sharing contracts and revenue-sharing contracts are two commonly discussed contracts, and most studies also conclude that the contracts can better coordinate the whole CLSC. In this paper, based on the above, we will expand on the decision problem of considering members' offline collecting channels in CLSC.

In the CLSC, collecting and remanufacturing activities have a crucial role, and the research on the collecting channel of the CLSC has been a key direction in recent years. In the CLSC collecting channel research problem, manufacturing and remanufacturing activities also have a great influence on the arrangement of collecting channels and collecting pricing decisions. In the existing research on the problem of CLSC collecting channel, no scholars have considered the capacity constraint and capacity investment decision of manufacturers' manufacturing/remanufacturing activities. It can be seen from the actual situation that manufacturers' capacity must have a certain specific upper limit, and cannot arrange manufacturing and remanufacturing activities without limitation. For example, the production capacity of automobile engine remanufacturers Cummins, Doyts and Mercedes-Benz only 3000 vehicles per year; Wuxi Diesel Plant, located in Jiangsu Province, produces only 5000 remanufactured vehicles per year. Obviously, the development strategies of enterprises are affected by their production capacity, and the capacity constraint on remanufacturing activities also affects their decision making on the amount of collecting and pricing of remanufactured products, which further affects the positive benefits of collecting and remanufacturing activities to the environment. Under the condition of capacity constraint, capacity investment is a common solution nowadays. Taiwan Semiconductor Manufacturing Corporation (TSMC) has invested $\$ 12$ billion in advance to expand its capacity to win chip orders from large buyers [10]. In the CLSC, as there are two kinds of manufacturing activities, how to make reasonable and appropriate investment in manufacturing and remanufacturing capacity, respectively, is a headache for manufacturers. In 2007, the three major U.S. automakers, General Motors, Ford, and Chrysler, made capacity investments in manufacturing and remanufacturing activities in advance to cope with the pressure of demand and competition; this wise investment decision earned them higher revenue [11]. When and how to make the right capacity investments is extremely important for a company's competitiveness in the market and future growth prospects. Second, capacity investment behavior affects manufacturers' manufacturing and remanufacturing activities, which in turn has an impact on collection decisions, and determines the sustainability and environmental benefits of the CLSC. Therefore, this paper will study the impact of capacity investment on the collection decision problem of the CLSC under the premise of considering capacity constraints.

From the existing research on CLSC collecting channels, most scholars discuss the collecting channels mainly: manufacturer collecting, retailer collecting and the third-party collector collecting, while supplier collecting should also be one of the options. Generally 
speaking, the manufacturer needs to be supplied with components by the supplier, who should have a better understanding of the components and can more easily control the quality of recycled product parts. At the same time, strategic interactions between the manufacturer and the supplier are becoming more frequent, and this interaction will have a significant impact on the economic and environmental performance of the CLSC. As a result, product collecting can be done by the supplier who has a close relationship with the manufacturer. An important difference between the supplier collecting channel and other collecting channels is that the supplier's collecting decisions affect the wholesale price of components they offer to the manufacturer, which in turn affects the suppliermanufacturer relationship. In fact, some companies have decided to work with their suppliers. For example, companies such as Caterpillar will transfer the collecting segment, and even remanufacturing activities, to their key component suppliers [12]. Therefore, in this paper, we further introduce the channel of supplier collecting into the CLSC collecting channel decision problem considering capacity constraints and capacity decisions, and compare and analyze the impact of supplier collecting channel on the optimal decision of the CLSC, as well as the environmental benefits of the CLSC.

In the above CLSC that considers the supplier collecting channel, the relationship between the manufacturer and the supplier becomes complex, and this relationship may be a competitive one or a cooperative one, so it is essential to consider coordinated cooperation between the manufacturer and the supplier. Companies such as Apple and Foxconn have long had good cooperative exchange relationships with their own suppliers [13]; companies such as Caterpillar, on the other hand, have constituted cooperative relationships with their key component suppliers in collecting, and even remanufacturing activities [12]. It can be seen that how to eliminate the double marginalization effect among members without reducing the overall benefit of the supply chain, and ensure the profit maximization of members and the whole CLSC is a problem that needs to be considered and solved. In addition to wholesale price contracts and revenue-sharing contracts, the combined use of multiple coordination contracts has become an important research phenomenon. In addition, compared with one-way coordination and cooperation, two-way coordination is more conducive to communication and sharing among members and is more advantageous for improving members' profitability. In this paper, we propose a two-way cost-sharing contract in the studied CLSC collecting channel decision problem and investigate whether this two-way coordination approach can better coordinate the CLSC. Inspired by the above studies and examples, we set out to study the capacity constraints and investments in closed-loop supply chains, while introducing new collectors and coordination mechanisms, in the hope of achieving greater sustainability in the supply chain. In this paper, we intend to address the following questions: What is the impact of capacity constraints on the optimal decision of supply chain members? How to make the most appropriate capacity investment? Who are the best collectors in different scenarios? How can coordination contracts be arranged to enhance the sustainability of closed-loop supply chains?

This paper studies the CLSC that consists of one manufacturer and one supplier, the manufacturer conducts the manufacturing activities of products, and the components required by the manufacturer are supplied by the supplier. The manufacturer is also responsible for remanufacturing secondhand products, and the recycled components required for remanufacturing are provided by either the supplier or the manufacturer itself. The manufacturing and remanufacturing production capacities are constrained, and all market needs are to be satisfied simultaneously. However, the manufacturer has the ability to invest in capacity. Furthermore, it is assumed that the collecting of used products can be completed by the supplier and the manufacturer. Cooperative contracts are also studied in this paper. Two kinds of cooperation are considered: cost-sharing contracts and two-way coordination contracts. The above cooperation is established between the manufacturer and the supplier. The supplier has higher pricing power than the manufacturer. First, the supplier defines its optimal prices of those two kinds of modules. Then, the manufacturer determines its optimal prices of the two kinds of products. Based on the assumptions, 
the market demand of the two products can be subsequently determined. The production of a product needs a one-unit module, and then the quantity of the components required by the manufacturer is determined. Under such a supply chain structure and conditions, five models are formulated: the manufacturer collecting scenario without a contract (Scenario $\mathrm{MC}$ ); the supplier collecting scenario without a contract (Scenario SC); the manufacturer collecting scenario with a contract (Scenario MS); the supplier collecting scenario with a contract (Scenario SS); and the supplier collecting scenario with a double coordination contract (Scenario SD). Through these models, the optimal decisions, such as the pricing decisions, collecting decisions and capacity allocating decisions of the CLSC members, are discussed. Additionally, the impacts of these parameters on pricing and channel decisions are studied.

The main innovative contributions of this paper can be summarized as follows. First, in order to make the model more realistic, this study adds conditional constraints to the decision problem regarding collecting channels in the closed-loop supply chain, setting an upper limit on the manufacturer's manufacturing and remanufacturing capacity, and adding a new decision variable, the amount of capacity investment, to achieve higher revenue and environmental benefits in the CLSC. Secondly, for the purpose of expecting manufacturers to be committed to remanufacturing, collecting channels are added, and collecting activities are assigned to the supplier who is more familiar with the quality of parts, comparing the differences between manufacturer collecting and supplier collecting models. Third, it is proposed to construct a two-way coordination contract between the manufacturer and the supplier, in which the manufacturer share the collecting costs of the supplier and the supplier share the investment costs of the manufacturer, in order to improve the efficiency of cooperation, reduce the double marginalization effect, improve the benefits of members, and enhance the environmental benefits of the CLSC. This paper is the first study of capacity investment, collecting channels and pricing decisions in CLSC considering capacity constraints and two-way coordination contracts.

The rest of this paper is structured as follows. Section 2 briefly reviews some relevant literature. Section 3 presents the basis of the model's formulation, such as the relevant notations and assumptions. Section 4 formulates those models, and the optimal decisions of members are compared. In Section 5, a numerical analysis is conducted, and the effects of five important coefficients on decisions are analyzed. The last section concludes this paper.

\section{Literature Review}

In the existing literature, there are many CLSC studies focusing on the chain structure, the coordination of chain members, collection channels and optimal determinations and so on. In this section, the studies related to this paper are reviewed briefly.

In recent years, due to the higher awareness of environmental protection and sustainability concepts, an increasing number of scholars have begun to study the CLSC with remanufacturing activities. Many scholars have studied different structures of this kind of CLSC. Wan and Hong [14] study a CLSC with an independent manufacturer and two recyclers, and the recycling process is completed with dual collection channels. The results show that remanufacturing activities can stimulate consumption. Comprising one manufacturer, one supplier and one third-party collector, a CLSC in which used products from the market are recycled is addressed by Wang et al. [15,16] and Lee [17]. Wang et al. [15] assume that the supplier and the collector are competitive, and the optimal recycling strategies are derived. Lee [17] establishes and analyzes six different Stackelberg game models. A comparison and analysis reveal that the CLSC's win-win situation must be based on the premise that all members participate in green activities. Li et al. [18] investigate a CLSC comprising one manufacturer and one retailer, in which the retailer completes recycling activities. By formulating a dynamic pricing game model, they discuss the optimal pricing decisions of CLSC members. Zheng et al. [19] investigate a three-echelon CLSC, where the manufacturer completes manufacturing, recycling and remanufacturing activities independently. In the study of decision problems regarding recycling channels in closed-loop 
supply chains, a review of many relevant papers clearly shows that many scholars discuss a CLSC consisting of a manufacturer and a retailer [3,5,20-22]. Few studies consider the structure of the CLSC composed of one supplier and one manufacturer. Based on this common structure, Ji et al. [5] multiple recovery and warranty channels are discussed. Wen et al. [20] discuss the pricing decisions of the retailer. The conclusion shows that an equal-pricing strategy is the optimal strategy. Mondal and Giri [21] assume that the manufacturer recycles and remanufactures reused products by itself. Wan [23] considers the CLSC structure with government subsidies and to discuss the optimal decisions, formulates nine different decision models under three kinds of collection modes and three kinds of power structures. Wang et al. [24] also study the retailer collection modes.

The research topic, the production capacity constraint problem, is also related to the analysis conducted in this paper. In many studies, the capacity of production is unlimited. However, the reality is that no manufacturer can manufacture products without the limitation of manufacturing capacity, and this capacity cap has many important influences on the CLSC members' decisions. Wu et al. [25] discuss a two-echelon CLSC composed of one supplier and two manufacturers, in which these manufacturers have asymmetric capacity constraints. Through calculation and analysis, different information sharing plans are formulated. The result shows how the manufacturer's information sharing mechanism is affected by the supplier's pricing decision. A two-stage decentralized supply chain [26], in which the manufacturers' production capacity is limited, is studied. Hsieh and Lai [26] analyze the manufacturers' capacity allocation and pricing decisions and study how some factors affect the manufacturers' decisions and profits, revealing that the influence of some parameters on revenue depends on the expected demand. Due to the existence of restrictive price caps, the situation is more serious when there is a capacity limit. Atamer et al. [27] explore the influence of capacity constraints on optimal equilibrium conditions, such as pricing and production, and find that the upper limit of production capacity will affect the manufacturers' decisions. As the previous literature rarely considers capacity constraints, the upper limit of the capabilities of the manufacturer is considered in our models.

In addition to the different supply chain structures and capacity constraint discussed above, coordination and cooperation among chain members have also been widely discussed. Under a CLSC framework, how can members be motivated to cooperate and improve their profit? To solve this problem, scholars discuss CLSCs and consider various cooperation methods, such as quantity discounts, cost-sharing contracts, revenue-sharing contracts, and buy-back contracts. Zheng et al. [19] discuss three kinds of cooperative models (a centralized model, a manufacturer and distributor cooperation model, and a distributor and retailer distributor model) and consider the fairness concerns of the retailer. The cooperation method is a coalition structure, and the results can help chain managers understand the optimal option. Xiang and $\mathrm{Xu}$ [28] consider cost-sharing contracts between the retailer and the Internet service platform and revenue-sharing contracts between the manufacturer and the retailer. Their results show that contracts have positive impacts on the development of the industry and the supply chain's sustainability. Considering carbon emission reduction in pricing decisions, Li et al. [29] research one-way and two-way cost-sharing contracts. The results show that the two-way cost-sharing cooperative method is optimal. Zheng et al. [30] study five different coalition decisions models. In the study of decision problems regarding collecting channels in closed-loop supply chains, revenuesharing and cost-sharing contracts are the two most frequently discussed types of contracts. Zou et al. [31] discuss a supply chain consisting of a manufacturer and two competing retailers and examine the impact of revenue-sharing covenants on coordination, considering the two-way risk aversion characteristics of the members. The authors find that the optimal ratio obtained through the revenue-sharing contract can improve the chain members' profit. Yuan et al. [32] analyze some necessary conditions of the manufacturer, the retailer, and the online collector to achieve interest coordination. Ji et al. [5] consider two types of covenants to study multiple recycling channels and warranty channels. The research on two-way coordination contracts is currently not extensive. Information asymmetry in this situation 
often affects the efficiency and profitability of the enterprise. Therefore, based on the above studies, this paper proposes building a double coordination contract between the supplier and the manufacturer.

The review of the above literature shows that the closed-loop supply chain recovery channel is the most discussed in most of the studies on the decision problem $[5,7,33]$. However, this study is different from the existing studies. In this study, the CLSC is composed of one supplier and one manufacturer, the manufacturer has capacity constraints, and the manufacturer can enhance their capacities through capacity investment. Additionally, the supplier collects used products from the market, denoting a collecting method different from the manufacturer and third-party collecting methods in existing research. Three cooperation methods are proposed, and two contracts are considered: cost-sharing contracts and two-way coordination contracts. Among them, the cost-sharing contracts are discussed in most existing studies [32,33], while two-way coordination contracts are rarely studied in the existing literature. Then, the optimal pricing decision and collecting channel option under two kinds of collecting scenarios (supplier collection and manufacturer collection) are discussed. We also analyze the influence of some important factors, such as the customer's price sensitivity and the cost-sharing and revenue-sharing ratio, on the CLSC members' pricing and channel decisions.

\section{Problem Basics}

\subsection{Problem Description}

This paper studies a CLSC composed of one supplier, called Player S, and one manufacturer, called Player M. Each member aims to maximize its own profit. Further, the information in this CLSC is symmetric such that all CLSC members acquire the same information as they are determining decisions. Based on the supplier's decisions and the market demand, the manufacturer needs to determine its best prices. According to the reaction of the manufacturer, the supplier and the market determine the best decisions.

In the following, we formulate five different models: the manufacturer collecting scenario without a contract (Scenario MC); the manufacturer collecting scenario with a contract (Scenario MS); the supplier collecting scenario without a contract (Scenario SC); the supplier collecting scenario with a contract (Scenario SS); and the supplier collecting scenario with a double coordination contract (Scenario SD). In the five scenarios, the decision sequences are divided into two cases. When the manufacturer collects, first, the supplier decides its best price $p_{1}$, then the manufacturer determines the remanufactured products best price $p_{r}$ and then determines the collecting rate $\tau$ and the new products' best price $p_{n}$ according to the decisions of the supplier. The difference between those models lies in the member responsible for the collecting process. In Scenario MC and Scenario MS, the manufacturer is responsible for collecting; in Scenario SC, Scenario SS and Scenario SD, the supplier collects the used products from the market. Two different contracts between chain members are studied: a cost-sharing contract and a two-way coordination contract. In Scenario SD, we also consider a two-way cooperation contract to increase the profit of the CLSC members. Figure 1 shows the structure of the CLSC when participants are making decisions.

In this structure, the supplier supplies the components to the manufacturer. The manufacturer will manufacture new products by purchasing those components from the supplier and sell new products to consumers directly. Additionally, the manufacturer can also produce the remanufactured products using recycled components, which are collected independently or purchased from the supplier, and can sell remanufactured products to the consumers directly. The collecting process is completed by different members (either the supplier or the manufacturer) in different models. Both the manufacturing and remanufacturing capacity have constraints; however, the manufacturer can extend its production capacity through capacity investment, where the investment cost can be viewed as a linear function of investment volume [34]. The market has different preferences for the two kinds of products, the demand and price are linearly related, and the market is price sensitive. 


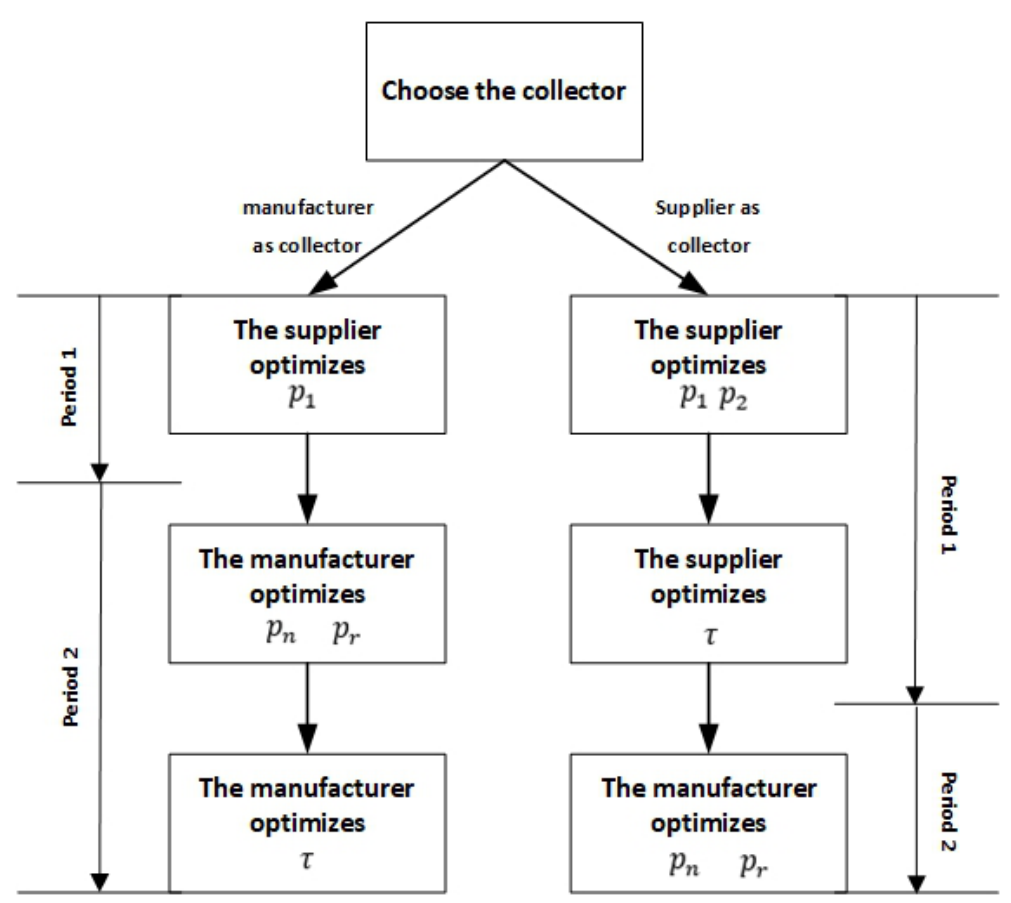

Figure 1. The decision-making sequence.

\subsection{Notations}

The notations used in the model are listed below Table 1:

Table 1. Notations.

\begin{tabular}{|c|c|}
\hline \multicolumn{2}{|c|}{ Parameters } \\
\hline$r$ & The cost of the capacity investment coefficient \\
\hline$\sigma$ & $\begin{array}{l}\text { The customer preference coefficient on remanufactured products; the customer preference } \\
\text { coefficienton new products can be defined as }(1-\sigma) \text {; refer to [30] }\end{array}$ \\
\hline$\mu$ & The cooperator investment cost-sharing ratio \\
\hline$\eta$ & The cooperator recovery cost-sharing ratio \\
\hline$Q$ & Total market potential demand of the products \\
\hline$\phi_{i}$ & $\begin{array}{l}\text { The cap of manufacturer production capacity; the } i \text { in the subscript will take value } 1 \text { and } 2 \text {, which } \\
\text { denote different production activities }\end{array}$ \\
\hline$c_{S}$ & The unit cost paid by the supplier for providing one new component \\
\hline$c_{L}$ & The scaling parameter for a return; analogous to [21] \\
\hline$c_{m}$ & The unit cost paid by the manufacturer for manufacturing one new product \\
\hline$c_{r}$ & The unit cost paid by the manufacturer for remanufacturing one remanufactured product \\
\hline$\Delta$ & The unit cost saved by remanufacturing compared to manufacturing, $\Delta=c_{m}-c_{r}>0$ \\
\hline $\bar{c}$ & The average cost of producing one unit of product, $\bar{c}=c_{m}(1-\tau)+c_{r} \tau=c_{m}-\Delta \tau$; analogous to $[6,16]$ \\
\hline$A, B$ & Characters used to simplify the expression of the result of the calculations, no real meaning \\
\hline$U, X, V$ & Characters used to replace complex expressions, no real meaning \\
\hline \multicolumn{2}{|c|}{ Decision Variables } \\
\hline$p_{1}^{j}$ & The unit price of one new component \\
\hline$p_{2}^{\frac{1}{j}}$ & The unit price of one reused component \\
\hline$\tau_{k}^{j}$ & The collection rate of the used product \\
\hline$p_{n}{ }^{j}$ & The unit price set by the manufacture for new products \\
\hline$p_{r}^{j}$ & $\begin{array}{l}\text { The unit price set by the remanufacturer for remanufactured products } \\
j \text { in the superscript takes the values } M C, S C \text { and } M S, S S \text {, and } S D \text {, which denote different scenarios; } k \text { in the } \\
\text { subscript takes the values } M \text { and } S, \text { which denote different collectors. }\end{array}$ \\
\hline
\end{tabular}


Table 1. Cont.

\begin{tabular}{ll}
\hline Derived Variables & \\
\hline$q_{n}{ }^{j}$ & The market demand of the new products \\
$q_{r}{ }^{j}$ & The market demand of the remanufactured products \\
$k_{1}{ }^{j}$ & The amount of manufacturer's capacity investment for manufacturing \\
$k_{2}{ }^{j}$ & The amount of manufacturer's capacity investment for remanufacturing \\
$\Pi_{M}{ }^{j}$ & The profit of the manufacturer \\
$\Pi_{S}{ }^{j}$ & The profit of the supplier \\
$\Pi_{T}{ }^{j}$ & The profit of the CLSC \\
& $j$ in the superscript takes the values MC, SC and MS, SS, and SD, which denote different scenarios. \\
\hline
\end{tabular}

\subsection{Assumptions}

Our models are formulated under these assumptions.

Assumption 1. The production capacities of manufacturing and remanufacturing have constraints, and unlimited production is not possible. The production capacity of both has a cap.

Assumption 2. The two kinds of products are different for consumers, and they have different market preferences.

Assumption 3. This paper assumes that the market demand is larger than the production capacity and that the demand of the end market should be satisfied. Therefore, the manufacturer and the remanufacturer need to extend their capacity through capacity investment. Let rk be the investment cost, which indicates that the investment cost is a linear function of the amount of investment, analogous to Xie and Han [34].

Assumption 4. The demand of the market is linear and dependent on the price, and the potential market is normalized to 1 [30].

Assumption 5. The collector of used products should bear the costs incurred in the collecting process, which is the convex growth function of the collection rate and can be expressed as $c_{L} \tau_{k}^{2}$ [21].

Assumption 6. The information obtained by each member is symmetric, and all games are complete information games.

\section{Model Formulations and Solutions}

This paper researches a CLSC composed of one supplier and one manufacturer. The whole potential demand is $Q$; therefore, the demand of new products can be expressed as $q_{n}=Q-\frac{p_{n}+p_{r}}{1-\sigma}$, and the demand of remanufactured products is $q_{r}=\frac{\sigma p_{n}-p_{r}}{\sigma(1-\sigma)}$. In these functions, $k_{1}=q_{n}-\phi_{1}$, and $k_{2}=q_{r}-\phi_{2}$. Both manufacturing and remanufacturing have a production capacity constraint $\phi_{1}$ and $\phi_{2}$, which cannot satisfy the market demand; therefore, they need to extend their production capacity through capacity investment. The investment cost of manufacturing and remanufacturing can be described as a linear function of investment volume, $c_{1}=r k_{1}$ and $c_{2}=r k_{2}$, respectively. In this section, the optimal decision values in different scenarios are solved.

\subsection{The Manufacturer Collecting Scenario}

\subsubsection{Without Cooperation Contract (Scenario MC)}

In this scenario, the supplier is assumed to be the leader of the Stackelberg game, and the manufacturer is the follower. The supplier determines its pricing decision of components to maximize its own profit. According to the decision of the supplier, the manufacturer decides the best recovery rate and then makes its pricing decisions. All members 
of the CLSC aim to maximize their own profit. Furthermore, the collection process is completed by the manufacturer in this model.

The supplier determines $p_{1}^{M C}$, the optimal price of new parts. Then, the manufacturer reacts and decides simultaneously the optimal price of two kinds of products, namely, $p_{n}^{M C}$ and $p_{r}^{M C}$, and finally determines the recovery rate $\tau_{M}^{M C}$.

The manufacturer's profit expression is as follow:

$$
\begin{aligned}
\max \Pi_{M}^{M C *} & =\left(p_{n}^{M C *}-p_{1}^{M C *}\right) q_{n}^{M C *}+p_{r}^{M C *} q_{r}^{M C *}-r k_{1}^{M C *}-r k_{2}^{M C *}-\bar{c}\left(q_{n}^{M C *}+q_{r}^{M C *}\right) \\
& -c_{L} \tau_{M}^{M C *^{2}}
\end{aligned}
$$

subject to $\phi_{1} \leq q_{n}^{M C *}, \phi_{2} \leq q_{r}^{M C *}$

The supplier's profit expression is as follow:

$$
\max \Pi_{S}^{M C *}=\left(p_{1}^{M C *}-c_{S}\right) q_{n}^{M C *}
$$

Theorem 1. The profit function of the manufacturer is concave with respect to $p_{n}^{M C}, p_{r}^{M C}$ and $\tau_{M}^{M C}$. The profit expression of the supplier is concave with respect to $p_{1}^{M C}$.

Then, the backward induction method can be used to obtain these optimal determinants of the chain members.

For the manufacturer, $p_{n}^{M C}$ and $p_{r}^{M C}$ are determined first and from the first-order conditions of optimization, $\frac{\partial \Pi_{M}^{M C}}{\partial \tau_{M}^{M C}}=0$. The optimal solution can be obtained.

$$
\tau_{M}^{M C *}=\frac{\Delta Q}{2 c_{L}}-\frac{\Delta(1+\sigma)}{2 c_{L} \sigma(1-\sigma)} p_{r}^{M C *}
$$

Proposition 1. In Model MC, the collection rate of manufacturer $\tau_{M}^{M C}$ decreases as the price of the remanufactured product set by manufacturer $p_{r}^{M C}$ increases.

There is a negative correlation between the recovery rate and the selling price of re-products. The higher the selling price is, the lower the recovery rate. When the price of remanufactured products is too high, the price-sensitive market demand will inevitably decrease. Therefore, manufacturers will choose to reduce the production of remanufactured products to avoid losses caused by oversupply, which will lead to a reduction in collecting activities. How to determine the appropriate price to balance demand and revenue is a problem that manufacturers need to consider.

For the manufacturer, from the first-order conditions of optimization, $\frac{\partial \Pi_{M}^{M C}}{\partial p_{n}^{M C}}=0$. The optimal solution can be obtained.

$$
p_{n}^{M C *}=\frac{(1-\sigma) Q}{2}+\frac{1}{2} p_{1}^{M C *}
$$

Proposition 2. In Model MC, the optimal pricing of the manufacturer for selling the new products $p_{n}^{M C}$ increases with the unit price of a new component $p_{1}^{M C}$.

The above shows that the price of a new product is positively correlated with the price of its components. This is in line with reality. As the price of purchased components rises, the manufacturer's pressure on product manufacturing also increases. To obtain revenue, the selling price of products can only be increased. Since the model is more ideal than the actual model, a simple linear relationship appears here. Recently, under the influence of the COVID-19 pandemic, the supply chain of many automobile manufacturing industries has fluctuated. Almost all parts suppliers have joined the price increase camp. Take our common product tires as an example; in March, Michelin started to increase prices in the 
US market by $7 \%$ and in the Canadian market by $5 \%$, all of which will result in price changes in the auto industry in the future.

Substituting the above result Equation (3) into the calculation, the manufacturer sets their wholesale price of the remanufactured products as follows:

$$
p_{r}^{M C *}=B_{1} p_{1}^{M C *}+A_{1}
$$

where $A_{1}=\frac{2 c_{L} \sigma^{2}(1-\sigma)\left(c_{m}+r-\frac{\Delta^{2} Q}{2 c_{L}}\right)}{4 c_{L} \sigma(1-\sigma)-\Delta^{2}(1+\sigma)^{2}}, B_{1}=\frac{2 c_{L} \sigma\left(1-\sigma^{2}\right)}{4 c_{L} \sigma(1-\sigma)-\Delta^{2}(1+\sigma)^{2}}$.

Proposition 3. In Model MC, if the price of the remanufactured product set by manufacturer $p_{r}^{M C}$ decreases, the unit price of one new component set by supplier $p_{1}^{M C}$ increases; otherwise, $p_{r}^{M C}$ increases with $p_{1}^{M C}$.

Sometimes, there is also a negative correlation between the selling price and the supply price, which can be regarded as competition between two kinds of products. This also reminds the manufacturing industry that looking for suppliers with suitable quotations will indirectly affect the proportion of remanufactured products' demand, thereby affecting the sustainable development of the industry.

Given the manufacturer's pricing decisions, the supplier has the best reactions of $p_{n}^{M C}$. For the supplier, the first-order condition of optimization is $\frac{\partial \Pi_{S}^{M C}}{\partial p_{1}^{M C}}=0$. The optimal solution can be obtained.

$$
p_{1}^{M C *}=\frac{Q(1-\sigma)-2 A_{1}}{2+4 B_{1}}+\frac{1}{2} c_{s}
$$

Proposition 4. In Model MC, if $\Delta^{2}>8 \sigma c_{L}$, the unit price of one new component set by supplier $p_{1}^{M C}$ decreases with the cost of the capacity investment coefficient $r$; otherwise, the relationship between them cannot be determined. Besides, there is a linear correlation between $p_{1}^{M C}$ and $r$.

Proof of Proposition 4. From above calculation, we can obtain:

$$
\begin{gathered}
p_{1}^{M C *}=\frac{Q(1-\sigma)-2 A_{1}}{2+4 B_{1}}+\frac{1}{2} c_{S} \\
=\frac{Q(1-\sigma)\left(4 c_{L} \sigma(1-\sigma)-\Delta^{2}(1+\sigma)^{2}\right)-4 c_{L} \sigma^{2}(1-\sigma)\left(c_{m}+r-\frac{\Delta^{2} Q}{2 c_{L}}\right)}{8 c_{L} \sigma(1-\sigma)-2 \Delta^{2}(1+\sigma)^{2}+8 c_{L} \sigma\left(1-\sigma^{2}\right)}+\frac{1}{2} c_{s} \\
\frac{\partial p_{1}^{M C *}}{\partial r}=\frac{-4 c_{L} \sigma^{2}(1-\sigma)}{8 c_{L} \sigma(1-\sigma)(2+\sigma)-2 \Delta^{2}(1+\sigma)^{2}}
\end{gathered}
$$

From the assumptions, $\sigma \in(0,1)$, so $1-\sigma>0$, then $-4 c_{L} \sigma^{2}(1-\sigma)<0$ is constant; and $(1-\sigma)(2+\sigma) \in(0,2),(1+\sigma)^{2} \in(1,4)$.

Then it can be obtained: $8 c_{L} \sigma(1-\sigma)(2+\sigma)<16 c_{L} \sigma, 2 \Delta^{2}(1+\sigma)^{2}>2 \Delta^{2}$.

Hence, as $16 c_{L} \sigma<2 \Delta^{2}$, we can obtained $8 c_{L} \sigma(1-\sigma)(2+\sigma)<2 \Delta^{2}(1+\sigma)^{2}$, then $8 c_{L} \sigma(1-\sigma)(2+\sigma)-2 \Delta^{2}(1+\sigma)^{2}<0, \frac{\partial p_{1}^{M C *}}{\partial r}>0$; otherwise, the relationship cannot be determined.

Substituting the above result into the calculation, the capacity investment of manufacturing and the capacity investment of remanufacturing can be expressed as follows:

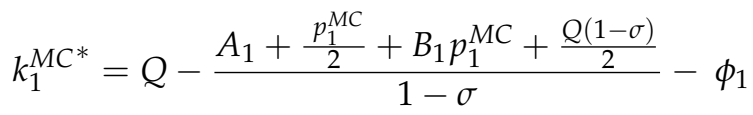




$$
k_{2}^{M C^{*}}=\frac{A_{1}+B_{1} p_{1}^{M C}-\sigma\left[\frac{p_{1}^{M C}}{2}+\frac{Q(1-\sigma)}{2}\right]}{\sigma(\sigma-1)}-\phi_{2}
$$

Proposition 5. In Model MC, we have the following:

[1] If $\underline{U}<U<0$, the amount of the manufacturer's capacity investment for manufacturing $k_{1}^{M C}$ increases with the unit price of one new component set by supplier $p_{1}^{M C}$; otherwise, $k_{1}^{M C}$ decreases as $p_{1}^{M C}$ increases. Where $\underline{\underline{U}}=-4 c_{L} \sigma(1-\sigma)^{2}, U=4 c_{L}\left(\sigma-\sigma^{2}\right)-\Delta^{2}(1+\sigma)^{2}$.

[2] If $0<U<\bar{U}$, the manufacturer's capacity investment for remanufacturing $k_{2}^{M C}$ decreases as the unit price of one new component set by supplier $p_{1}^{M C}$ increases; otherwise, $k_{2}^{M C}$ increases with $p_{1}^{M C}$. Where $\bar{U}=4 c_{L}\left(1-\sigma^{2}\right)$.

\section{Proof of Proposition 5.}

$$
\begin{aligned}
k_{1}^{M C^{*}} & =Q-\frac{A_{1}+\frac{p_{1}^{M C}}{2}+B_{1} p_{1}^{M C}+\frac{Q(1-\sigma)}{2}}{1-\sigma}-\phi_{1} \\
\frac{\partial k_{1}^{M C *}}{\partial p_{1}^{M C *}} & =-\frac{1}{2(1-\sigma)}-\frac{2 c_{L} \sigma(1+\sigma)}{4 c_{L}\left(\sigma-\sigma^{2}\right)-\Delta^{2}(1+\sigma)^{2}} \\
& =-\frac{4 c_{L}\left(\sigma-\sigma^{2}\right)-\Delta^{2}(1+\sigma)^{2}+4 c_{L} \sigma\left(1-\sigma^{2}\right)}{2(1-\sigma)\left[4 c_{L}\left(\sigma-\sigma^{2}\right)-\Delta^{2}(1+\sigma)^{2}\right]}
\end{aligned}
$$

We can treat $4 c_{L}\left(\sigma-\sigma^{2}\right)-\Delta^{2}(1+\sigma)^{2}$ as a quadratic function of $\sigma$.

If $4 c_{L}\left(\sigma-\sigma^{2}\right)-\Delta^{2}(1+\sigma)^{2}>0$, then $4 c_{L}\left(\sigma-\sigma^{2}\right)-\Delta^{2}(1+\sigma)^{2}+4 c_{L} \sigma\left(1-\sigma^{2}\right)>0$, $2(1-\sigma)\left[4 c_{L}\left(\sigma-\sigma^{2}\right)-\Delta^{2}(1+\sigma)^{2}\right]>0$, hence $\frac{\partial k_{1}^{M C *}}{\partial p_{1}^{M C *}}<0$.

If $4 c_{L}\left(\sigma-\sigma^{2}\right)-\Delta^{2}(1+\sigma)^{2}<-4 c_{L} \sigma\left(1-\sigma^{2}\right)$, then $4 c_{L}\left(\sigma-\sigma^{2}\right)-\Delta^{2}(1+\sigma)^{2}+4 c_{L} \sigma(1-$ $\left.\sigma^{2}\right)<0,2(1-\sigma)\left[4 c_{L}\left(\sigma-\sigma^{2}\right)-\Delta^{2}(1+\sigma)^{2}\right]<0$, hence $\frac{\partial k_{1}^{M C *}}{\partial p_{1}^{M C *}}<0$.

Otherwise, $\frac{\partial k_{1}^{M C *}}{\partial p_{1}^{M C *}}>0$.

$$
\begin{aligned}
k_{2}^{M C^{*}} & =\frac{A_{1}+B_{1} p_{1}^{M C}-\sigma\left[\frac{p_{1}^{M C}}{2}+\frac{Q(1-\sigma)}{2}\right]}{\sigma(\sigma-1)}-\phi_{2} \\
\frac{\partial k_{2}^{M C *}}{\partial p_{1}^{M C *}} & =\frac{1}{2(1-\sigma)}-\frac{2 c_{L}(1+\sigma)}{4 c_{L}\left(\sigma-\sigma^{2}\right)-\Delta^{2}(1+\sigma)^{2}} \\
& =\frac{4 c_{L}\left(\sigma-\sigma^{2}\right)-\Delta^{2}(1+\sigma)^{2}+4 c_{L}\left(1-\sigma^{2}\right)}{2(1-\sigma)\left[4 c_{L}\left(\sigma-\sigma^{2}\right)-\Delta^{2}(1+\sigma)^{2}\right]}
\end{aligned}
$$

Similarly, if $4 c_{L}\left(\sigma-\sigma^{2}\right)-\Delta^{2}(1+\sigma)^{2}>0$, then $4 c_{L}\left(\sigma-\sigma^{2}\right)-\Delta^{2}(1+\sigma)^{2}+4 c_{L}(1-$ $\left.\sigma^{2}\right)>0,2(1-\sigma)\left[4 c_{L}\left(\sigma-\sigma^{2}\right)-\Delta^{2}(1+\sigma)^{2}\right]>0$, hence $\frac{\partial k_{2}^{M C *}}{\partial p_{1}^{M C *}}>0$.

If $4 c_{L}\left(\sigma-\sigma^{2}\right)-\Delta^{2}(1+\sigma)^{2}<-4 c_{L} \sigma\left(1-\sigma^{2}\right)$, then $4 c_{L}\left(\sigma-\sigma^{2}\right)-\Delta^{2}(1+\sigma)^{2}+4 c_{L}(1-$ $\left.\sigma^{2}\right)<0,2(1-\sigma)\left[4 c_{L}\left(\sigma-\sigma^{2}\right)-\Delta^{2}(1+\sigma)^{2}\right]<0$, hence $\frac{\partial k_{2}^{M C *}}{\partial p_{1}^{M C *}}>0$.

Otherwise, $\frac{\partial k_{2}^{M C *}}{\partial p_{1}^{M C *}}<0$.

From the above, the relationship between the investment in manufacturing capacity $k_{1}^{M C}$ and the pricing of new components $p_{1}^{M C}$ and the relationship between the investment 
in remanufacturing capacity $k_{2}^{M C}$ and $p_{1}^{M C}$ must be opposite; that is, if the investment in manufacturing capacity is positively correlated with the pricing of new components, then the investment in remanufacturing capacity is negatively correlated with the pricing of new parts. When the pricing of modules increases, the investment in one type of production capacity will increase, while the investment in the other will decrease. The supplier's pricing of components can determine the manufacturer's production arrangements, which in turn affects the sustainability of the CLSC. The reasonable pricing of supplier is beneficial to the overall development of the CLSC.

According to the best reactions of members, we then obtain the optimal decisions of the CLSC.

$$
\begin{gathered}
p_{n}^{M C *}=\frac{c_{s}}{4}-\frac{2 A_{1}-Q(1-\sigma)}{2\left(4 B_{1}+2\right)}+\frac{Q(1-\sigma)}{2} \\
p_{r}^{M C *}=A_{1}+B_{1}\left[\frac{c_{s}}{2}-\frac{2 A_{1}-Q(1-\sigma)}{4 B_{1}+2}\right] \\
\tau_{M}^{M C *}=\frac{Q \Delta}{2 c_{L}}+\frac{\Delta\left\{A_{1}+B_{1}\left[\frac{c_{s}}{2}-\frac{2 A_{1}+Q(\sigma-1)}{4 B_{1}+2}\right]\right\}(\sigma+1)}{2 \sigma c_{L}(\sigma-1)} \\
k_{1}^{M C^{*}}=Q-\frac{A_{1}+\frac{c_{s}}{4}-\frac{2 A_{1}-Q(1-\sigma)}{2\left(4 B_{1}+2\right)}+\frac{Q(1-\sigma)}{2}+B_{1}\left[\frac{c_{s}}{2}-\frac{2 A_{1}-Q(1-\sigma)}{4 B_{1}+2}\right]}{1-\sigma}-\phi_{1} \\
k_{2}^{M C^{*}}=\frac{A_{1}+\sigma\left[\frac{2 A_{1}-Q(1-\sigma)}{2\left(4 B_{1}+2\right)}-\frac{c_{s}}{4}-\frac{Q(1-\sigma)}{2}\right]+B_{1}\left[\frac{c_{s}}{2}-\frac{2 A_{1}-Q(1-\sigma)}{4 B_{1}+2}\right]}{\sigma(\sigma-1)}-\phi_{2}
\end{gathered}
$$

Then, bringing the above results back to the income function, the maximum profit of CLSC members and the maximum revenue of this CLSC are calculated.

\subsubsection{With Cost-Sharing Contract (Scenario MS)}

In this model, the supplier is assumed to be the leader of the Stackelberg game, and the manufacturer is the follower. The supplier determines its pricing decision for components to maximize its own profit. Based on the decision of the supplier, the manufacturer decides the best recovery rate and then makes its pricing decisions. All members of the CLSC aim to maximize their own profit. Furthermore, the collecting process is completed by the manufacturer in this scenario, and the supplier shares the manufacturer's collecting cost.

The supplier decides $p_{1}^{M S}$, the optimal price of new components. Then, the manufacturer reacts and decides simultaneously the optimal price of two kinds of products, namely, $p_{n}^{M S}$ and $p_{r}^{M S}$, and finally determines the recovery rate $\tau_{M}^{M S}$. The decision sequence is the same as that in scenario MC.

The manufacturer's profit expression is as follows:

$$
\begin{aligned}
\max \Pi_{M}^{M S *} & =\left(p_{n}^{M S *}-p_{1}^{M S *}\right) q_{n}^{M S *}+p_{r}^{M S *} q_{r}^{M S *}-r k_{1}^{M S *}-r k_{2}^{M S *}-\bar{c}\left(q_{n}^{M S *}+q_{r}^{M S *}\right) \\
& -\mu c_{L} \tau_{M}^{M S *^{2}}
\end{aligned}
$$

subject to $\phi_{1} \leq q_{n}^{M S *}, \phi_{2} \leq q_{r}^{M S *}$

The supplier's profit expression is as follows:

$$
\max \Pi_{S}^{M S *}=\left(p_{1}^{M S *}-c_{S}\right) q_{n}^{M S *}-(1-\mu) c_{L} \tau_{M}^{M S *^{2}}
$$


Theorem 2. The profit function of the manufacturer is concave with respect to $p_{n}^{M S}, p_{r}^{M S}$ and $\tau_{M}^{M S}$. The profit expression of the supplier is concave with respect to $p_{1}^{M S}$.

For the manufacturer, $p_{n}^{M S}$ and $p_{r}^{M S}$ are determined first, and from the first-order condition of optimization, $\frac{\partial \Pi_{M}^{M S}}{\partial \tau_{M}^{M S}}=0$. The optimal solution can be obtained.

$$
\tau_{M}^{M S *}=\frac{\Delta Q}{2 \mu c_{L}}-\frac{\Delta(1+\sigma)}{2 \mu c_{L} \sigma(1-\sigma)} p_{r}^{M S *}
$$

Proposition 6. In Model MS, the collection rate of manufacturer $\tau_{M}^{M S}$ decreases as the price of the remanufactured product set by manufacturer $p_{r}^{M S}$ increases. The larger the investment cost-sharing ratio $\mu$ is, the smaller the change in $\tau_{M}^{M S}$ with $p_{r}^{M S}$.

For the manufacturer, $p_{1}^{M S}$ is known, and from the first-order condition of optimization, $\frac{\partial \Pi_{M}^{M S}}{\partial p_{n}^{M S}}=0$. The optimal solution can be obtained.

$$
p_{n}^{M S *}=\frac{(1-\sigma) Q}{2}+\frac{1}{2} p_{1}^{M S *}
$$

Substituting the above result Equation (16) into the calculation, the manufacturer sets the wholesale price of the remanufactured products as follows.

$$
p_{r}^{M S *}=B_{5} p_{1}^{M S *}+A_{5}
$$

where $A_{5}=\frac{2 \mu c_{L} \sigma^{2}(1-\sigma)\left(c_{m}+r-\frac{\Delta^{2} Q}{2 \mu c_{L}}\right)}{4 \mu c_{L} \sigma(1-\sigma)-\Delta^{2}(1+\sigma)^{2}}, B_{5}=\frac{2 \mu c_{L} \sigma\left(1-\sigma^{2}\right)}{4 \mu c_{L} \sigma(1-\sigma)-\Delta^{2}(1+\sigma)^{2}}$.

Proposition 7. In Model MS, if $4 \mu c_{L} \sigma(1-\sigma)<\Delta^{2}(1+\sigma)^{2}$, the price of the remanufactured product set by manufacturer $p_{r}^{M S}$ decreases as the unit price of one new component set by supplier $p_{1}^{M S}$ increases; otherwise, $p_{r}^{M S}$ increases with $p_{1}^{M S}$. The larger the investment cost-sharing ratio $\mu$ is, the smaller the change in $p_{r}^{M S}$ with $p_{1}^{M S}$.

Given the manufacturer's pricing decisions, the supplier has the best reactions of $p_{n}^{M S}$. For the supplier, from the first-order condition of optimization, $\frac{\partial \Pi_{S}^{M S}}{\partial p_{1}^{M S}}=0$. The optimal solution can be obtained.

$$
p_{1}^{M S *}=\frac{c_{L}(1-\sigma) \sigma^{2} \mu^{2}\left(Q-\sigma Q-2 A_{5}+c_{S}+2 B_{5} c_{S}\right)+\sigma B_{5} Q(1-\mu)\left(1-\sigma^{2}\right) \Delta^{2}}{(1-\mu) \Delta^{2}(1+\sigma)^{2} B_{5}^{2}+2 c_{L}(1-\sigma)\left(1+2 B_{5}\right) \sigma^{2} \mu^{2}}
$$

Proposition 8. In Model $M C$, if $4 \mu c_{L} \sigma(1-\sigma)<\Delta^{2}(1+\sigma)^{2}$, the unit price of one new component set by supplier $p_{1}^{M S}$ decreases with the cost of the capacity investment coefficient $r$; otherwise, $p_{1}^{M S}$ decreases as the cost of capacity investment coefficient $r$ increases. Besides, there is a linear correlation between $p_{1}^{M S}$ and $r$.

Substituting the above result into the calculation, the capacity investment of manufacturing can be expressed as follows.

$$
k_{1}^{M C^{*}}=Q-\frac{A_{5}+\frac{p_{1}^{M S}}{2}+B_{5} p_{1}^{M S}+\frac{Q(1-\sigma)}{2}}{1-\sigma}-\phi_{1}
$$

Furthermore, the capacity investment of remanufacturing can be expressed as:

$$
k_{2}^{M C^{*}}=\frac{A_{5}+B_{5} p_{1}^{M S}-\frac{\sigma}{2}\left[p_{1}^{M S}+Q(1-\sigma)\right]}{\sigma(\sigma-1)}-\phi_{2}
$$

Proposition 9. In Model MS, we have the following: 
[1] If $\underline{X}<X<0$, the amount of the manufacturer's capacity investment for manufacturing $k_{1}^{M S}$ increases with the unit price of one new component set by supplier $p_{1}^{M S}$; otherwise, $k_{1}^{M S}$ decreases as $p_{1}^{M S}$ increases. Where $\underline{X}=-4 c_{L} \mu \sigma^{2}(1-\sigma), X=4 c_{L}\left(\sigma-\sigma^{2}\right)-\Delta^{2}(1+\sigma)^{2}$.

[2] If $0<X<\bar{X}$, the manufacturer's capacity investment for remanufacturing $k_{2}^{M S}$ decreases as the unit price of one new component set by supplier $p_{1}^{M S}$ increases; otherwise, $k_{2}^{M S}$ increases with $p_{1}^{M S}$. Where $\bar{X}=4 c_{L} \sigma^{2}(1-\sigma)^{2}$.

The proof is similar with Proposition 5.

According to the best reactions of members, we then obtain the optimal decisions of the CLSC.

$$
\begin{aligned}
& p_{n}^{M C *}=\frac{c_{L} \sigma^{2} \mu^{2}(\sigma-1)\left(Q-2 A_{5}+c_{s}+2 B_{5} c_{s}-\sigma Q\right)-B_{5} Q \sigma \Delta^{2}\left(\sigma^{2}-1\right)(\mu-1)}{2\left[B_{5}{ }^{2} \Delta^{2}(\sigma+1)^{2}(\mu-1)+2 c_{L} \sigma^{2} \mu^{2}\left(2 B_{5}+1\right)(\sigma-1)\right]} \\
& -\frac{Q(\sigma-1)}{2} \\
& p_{r}^{M C *}=\frac{B_{5}\left[c_{L} \sigma^{2} \mu^{2}(\sigma-1)\left(Q-2 A_{5}+c_{s}+2 B_{5} c_{s}-\sigma Q\right)-B_{5} Q \sigma \Delta^{2}\left(\sigma^{2}-1\right)(\mu-1)\right]}{B_{5}^{2} \Delta^{2}(\sigma+1)^{2}(\mu-1)+2 c_{L} \sigma^{2} \mu^{2}\left(2 B_{5}+1\right)(\sigma-1)} \\
& +A_{5} \\
& \tau_{M}^{M C *}=\frac{\Delta\left\{A_{5}+\frac{B_{5}\left[c_{L} \sigma^{2} \mu^{2}(\sigma-1)\left(Q-2 A_{5}+c_{S}+2 B_{5} c_{s}-\sigma Q\right)-B_{5} Q \sigma \Delta^{2}\left(\sigma^{2}-1\right)(\mu-1)\right]}{B_{5}^{2} \Delta^{2}(\sigma+1)^{2}(\mu-1)+2 c_{L} \sigma^{2} \mu^{2}\left(2 B_{5}+1\right)(\sigma-1)}\right\}(\sigma+1)}{2 c_{L} \mu \sigma(\sigma-1)} \\
& +\frac{Q \Delta}{2 c_{L} \mu} \\
& k_{1}^{M C^{*}}=\frac{c_{L} \sigma^{2} \mu^{2}(\sigma-1)\left(Q-2 A_{5}+c_{s}+2 B_{5} c_{s}-\sigma Q\right)-B_{5} Q \sigma \Delta^{2}(\sigma+1)(\mu-1)}{2\left[B_{5}^{2} \Delta^{2}(\sigma+1)^{2}(\mu-1)+2 c_{L} \sigma^{2} \mu^{2}\left(2 B_{5}+1\right)(\sigma-1)\right]}\left(1+2 B_{5}\right) \\
& -\phi_{1}+\frac{Q}{2}-\frac{A_{5}}{(\sigma-1)} \\
& k_{2}^{M C^{*}}=\frac{c_{L} \sigma^{2} \mu^{2}\left(Q-2 A_{5}+c_{s}+2 B_{5} c_{s}-\sigma Q\right)-B_{5} Q \sigma \Delta^{2}(\sigma+1)(\mu-1)}{2\left[B_{5}^{2} \Delta^{2}(\sigma+1)^{2}(\mu-1)+2 c_{L} \sigma^{2} \mu^{2}\left(2 B_{5}+1\right)(\sigma-1)\right]}\left(2 B_{5}-1\right) \\
& +\frac{Q}{2}+\frac{A_{5}}{\sigma(\sigma-1)}-\phi_{2}
\end{aligned}
$$

Then, bringing the above results back to the income function, the maximum profit of CLSC members and the maximum revenue of this CLSC are calculated.

\subsection{The Supplier Collecting Scenario}

\subsubsection{Without Cooperation Contract (Scenario SC)}

In this model, the supplier is assumed to be the leader of the Stackelberg game, and the manufacturer is the follower. The supplier determines its best recovery rate and the aim of the supplier's pricing decision for components is to maximize its own profit. Based on the supplier's decision, the manufacturer makes its pricing decisions. All members of the CLSC aim to maximize their own profit. Furthermore, the collection process is completed by the supplier in this model.

The supplier determines $p_{1}^{S C}$ and $p_{2}^{S C}$, the optimal price of two kinds of components. Then, the supplier determines the best recovery rate $\tau_{S}^{S C}$, and the manufacturer reacts and decides simultaneously the optimal price of two kinds of products, namely, $p_{n}^{S C}$ and $p_{r}^{S C}$.

The manufacturer's profit expression is as follows:

$$
\max \Pi_{M}^{S C *}=\left(p_{n}^{S C *}-p_{1}^{S C *}\right) q_{n}^{S C *}+\left(p_{r}^{S C *}-p_{2}^{S C *}\right) q_{r}^{S C *}-r k_{1}^{S C *}-r k_{2}^{S C *}-\bar{c}\left(q_{n}^{S C *}+q_{r}^{S C *}\right)
$$


subject to $\phi_{1} \leq q_{n}^{S C *}, \phi_{2} \leq q_{r}^{S C *}$

The supplier's profit expression is as follows:

$$
\max \Pi_{S}^{S C *}=\left(p_{1}^{S C *}-c_{s}\right) q_{n}^{S C *}+p_{2}^{S C *} q_{r}^{S C *}-c_{L} \tau_{M}^{S C * 2}
$$

Theorem 3. The profit function of the manufacturer is concave with respect to $p_{n}^{S C}$ and $p_{r}^{S C}$. The profit expression of the supplier is concave with respect to $p_{1}^{S C}, p_{2}^{S C}$, and $\tau_{S}^{S C}$.

For the manufacturer, $p_{1}^{S C}$ and $p_{2}^{S C}$ are known, and from the first-order conditions of the optimization, $\frac{\partial \Pi_{M}^{S C}}{\partial p_{n}^{S C}}=0$, and $\frac{\partial \Pi_{M}^{S C}}{\partial p_{r}^{S C}}=0$. The optimal solutions can be obtained.

$$
\begin{gathered}
p_{n}^{S C *}=\frac{(1-\sigma) Q}{2}+\frac{1}{2} p_{1}^{S C *}-\frac{1}{2} p_{2}^{S C *} \\
p_{r}^{S C *}=\frac{\sigma p_{1}^{S C *}+p_{2}^{S C *}-(1+\sigma)\left(\Delta \tau_{S}-r-c_{m}\right)}{2}
\end{gathered}
$$

Proposition 10. In Model SC, we have the following:

[1] The optimal price of the manufacturer for selling the new products $p_{n}^{S C}$ increases with the unit price of a new component $p_{1}^{S C}$, and $p_{n}^{S C}$ decreases as the unit price of a reused component $p_{2}^{S C}$ increases.

[2] If $4 \sigma c_{L}(1-\sigma)>\Delta^{2}(1+\sigma)^{2}$, the optimal price of the remanufactured product $p_{r}^{M C}$ increases with $p_{1}^{S C}$ and $p_{2}^{S C}$; otherwise, $p_{r}^{M C}$ decreases as $p_{1}^{S C}$ and $p_{2}^{S C}$ increase.

The retail price is always opposite to the supply price of two kinds of components, which shows that the two kinds of components are in a competitive relationship. In addition, the retail price of a remanufactured product always has the same relationship with the supply price of the two parts, which means that the price changes of the two parts make no difference in the selling price of the remanufactured product.

For the supplier, $p_{1}^{S C}$ and $p_{2}^{S C}$ are determined first, and from the first-order condition of the optimization $\frac{\partial \Pi_{S}^{S C}}{\partial \tau_{S}^{S C}}=0$. The optimal solution can be obtained.

$$
\tau_{S}^{S C *}=A_{2} p_{1}^{S C *}+\frac{A_{2}}{\sigma} p_{2}^{S C *}-A_{2} C_{S}
$$

where $A_{2}=\frac{\Delta(1+\sigma)}{4 c_{L}(1-\sigma)}$

Proposition 11. In Model SC, the collection rate of supplier $\tau_{S}^{S C}$ increases with both the price of new components $p_{1}^{S C}$ and the price of reused components $p_{2}^{S C}$.

Given the manufacturer's pricing decisions, the supplier makes its best reactions. For the supplier, the first-order conditions of optimization are $\frac{\partial \Pi_{S}^{S C}}{\partial p_{1}^{S C}}=0$ and $\frac{\partial \Pi_{S}^{S C}}{\partial p_{2}^{S C}}=0$. The optimal solutions can be obtained.

$$
\begin{aligned}
& p_{1}^{S C *}=\frac{B_{2}+A_{3} B_{3}}{1-A_{3} A_{4}} \\
& p_{2}^{S C *}=\frac{B_{3}+A_{4} B_{2}}{1-A_{3} A_{4}}
\end{aligned}
$$

where $B_{2}=\frac{\frac{1-\sigma}{1+\sigma} Q-r-c_{m}+c_{s}-\Delta c_{s}}{2-\Delta A_{2}}, A_{3}=\frac{\Delta A_{2}}{\sigma\left(2-\Delta A_{2}\right)}, \quad B_{3}=\frac{\sigma^{2}(1-\sigma) Q-(1+\sigma)\left(r+c_{m}+\sigma \Delta A_{2} c_{s}\right)}{(1+\sigma)\left(2 \sigma-\Delta A_{2}\right)}$, $A_{4}=\frac{\Delta \sigma A_{2}}{2 \sigma-\Delta A_{2}}$. 
Proposition 12. In Model SC, if $\Delta^{2}(1+\sigma)^{2}>8 c_{L} \sigma(1-\sigma)$, the unit price of one new component set by supplier $p_{1}^{S C}$ increases with the cost of capacity investment coefficient $r$; otherwise, $p_{1}^{S C}$ increases as the cost of the capacity investment coefficient $r$ increases. Besides, there is a linear correlation between $p_{1}^{S C}$ and $r$. The proof is similar with Proposition 4.

Proposition 13. In Model SC, if $\Delta^{2}(1+\sigma)>8 c_{L}(1-\sigma)$, the unit price of the reused component set by supplier $p_{2}^{S C}$ decreases as the cost of the capacity investment coefficient $r$ increases; otherwise, $p_{2}^{S C}$ increases with the cost of the capacity investment coefficient $r$. Besides, there is a linear correlation between $p_{2}^{S C}$ and $r$. The proof is similar with Proposition 4.

The above derivation shows that representing a complex relationship, the relationship between the supply price of parts and the coefficient of the capacity investment cost is related to the value of the remanufacturing cost savings, the coefficient of the recovery cost, and market preferences.

Substituting the above result into the calculation, the capacity investment of manufacturing and the capacity investment of remanufacturing can be expressed as follows:

$$
k_{1}^{S C^{*}}=\frac{3}{2} Q+\frac{p_{1}^{S C}+\sigma p_{1}^{S C}+(\sigma+1)\left[c_{m}+r+\Delta A_{2}\left(c_{S}-p_{1}^{S C}+\frac{p_{2}^{S C}}{\sigma}\right)\right]}{2(1-\sigma)}-\phi_{1}
$$

Furthermore, the capacity investment of remanufacturing can be expressed as:

$$
\begin{aligned}
k_{2}^{S C^{*}} & =\frac{(\sigma+1)\left[c_{m}+r+\Delta A_{2}\left(c_{S}-p_{1}^{S C}+\frac{p_{2}^{S C}}{\sigma}\right)\right]}{2 \sigma(\sigma-1)} \\
& +\frac{p_{2}^{S C}+\sigma\left[p_{2}^{S C}-p_{1}^{S C}+Q(\sigma-1)\right]+\sigma p_{1}^{S C}}{2 \sigma(\sigma-1)}-\phi_{2}
\end{aligned}
$$

Proposition 14. In Model SC, we have the following:

[1] If $\Delta^{2}(1+\sigma)>V$, the amount of the manufacturer's capacity investment for manufacturing $k_{1}^{S C}$ increases with the unit price of one new component set by supplier $p_{1}^{S C}$; otherwise, $k_{1}^{S C}$ decreases as $p_{1}^{S C}$ increases; $k_{1}^{S C} 4$ increases with the unit price of one reused component set by supplier $p_{2}^{S C}$. Where $V=4 c_{L}(1-\sigma)$.

[2] If $\Delta^{2}(1+\sigma)<V$, the amount of the manufacturer's capacity investment for remanufacturing $k_{2}^{S C}$ increases with the unit price of one reused component set by the supplier $p_{2}^{M C}$; otherwise, $k_{2}^{S C}$ decreases as $p_{1}^{S C}$ increases; $k_{2}^{S C}$ increases with the unit price of one new component set by the supplier $p_{1}^{S C}$.

The proof is similar with Proposition 5.

According to the best reactions of members, we then obtain the optimal decisions of the CLSC:

$$
\begin{gathered}
p_{n}^{M C *}=\frac{B_{3}+A_{4} B_{2}-B_{2}+A_{3} B_{3}}{2\left(A_{3} A_{4}-1\right)}-\frac{Q(\sigma-1)}{2} \\
p_{r}^{M C *}=\frac{(\sigma+1)\left\{c_{m}+r+\Delta A_{2}\left[c_{s}+\frac{\left(B_{2}+A_{3} B_{3}\right)}{A_{3} A_{4}-1}-\frac{\left(B_{3}+A_{4} B_{2}\right)}{\sigma\left(A_{3} A_{4}-1\right)}\right]\right\}}{2} \\
-\frac{B_{3}+A_{4} B_{2}-\sigma\left(B_{2}+A_{3} B_{3}\right)}{2\left(A_{3} A_{4}-1\right)} \\
\tau_{M}^{M C *}=\frac{A_{2}\left(B_{3}+A_{4} B_{2}\right)}{\sigma\left(A_{3} A_{4}-1\right)}-\frac{A_{2}\left(B_{2}+A_{3} B_{3}\right)}{A_{3} A_{4}-1}-A_{2} c_{s}
\end{gathered}
$$




$$
\begin{aligned}
k_{1}^{M C^{*}}= & \frac{(\sigma+1)\left\{c_{m}+r+\Delta A_{2}\left[c_{s}+\frac{\left(B_{2}+A_{3} B_{3}\right)}{A_{3} A_{4}-1}-\frac{\left(B_{3}+A_{4} B_{2}\right)}{\sigma\left(A_{3} A_{4}-1\right)}\right]\right\}}{2(\sigma-1)} \\
& +\frac{\frac{(1+\sigma)\left(B_{2}+A_{3} B_{3}\right)}{A_{3} A_{4}-1}}{2(\sigma-1)}+\frac{Q}{2}-\phi_{1} \\
k_{2}^{M C^{*}}= & \frac{(\sigma+1)\left\{c_{m}+r+\Delta A_{2}\left[c_{s}+\frac{\left(B_{2}+A_{3} B_{3}\right)}{A_{3} A_{4}-1}-\frac{\left(B_{3}+A_{4} B_{2}\right)}{\sigma\left(A_{3} A_{4}-1\right)}\right]\right\}+\frac{\sigma\left(B_{2}+A_{3} B_{3}\right)}{A_{3} A_{4}-1}}{2 \sigma(\sigma-1)} \\
- & \frac{Q}{2}-\phi_{2}-\frac{(1+\sigma)\left(B_{3}+A_{4} B_{2}\right)+\sigma\left(B_{2}+A_{3} B_{3}\right)}{2 \sigma(\sigma-1)\left(A_{3} A_{4}-1\right)}
\end{aligned}
$$

Then, bringing the above results back to the income function, the maximum profit of CLSC members and the maximum revenue of this CLSC are calculated.

\subsubsection{With Cost-Sharing Contract (Scenario SS)}

In this scenario, the supplier is assumed to be the leader of the Stackelberg game, and the manufacturer is the follower. The supplier determines the best recovery rate, and the aim of the supplier's pricing decisions for components is to maximize its own profit. Based on the supplier's decision, the manufacturer makes its pricing decisions. All members of the CLSC aim to maximize their own profit. Furthermore, the collecting process is completed by the supplier in this scenario, and the manufacturer shares the supplier's collecting cost.

The supplier decides $p_{1}^{S S}$ and $p_{2}^{S S}$, the optimal price of two kinds of components. Then, the supplier determines the best recovery rate $\tau_{S}^{S S}$, and the manufacturer reacts and determines simultaneously the optimal price $p_{n}^{S D}$ and $p_{r}^{S D}$, namely, $p_{n}^{S S}$ and $p_{r}^{S S}$.

The manufacturer's profit expression is as follows:

$$
\begin{aligned}
\max \Pi_{M}^{M C *} & =\left(p_{n}^{S S *}-p_{1}^{S S *}\right) q_{n}^{S S *}+\left(p_{r}^{S S *}-p_{2}^{S S *}\right) q_{r}^{S S *}-r k_{1}^{S S *}-r k_{2}^{S S *}-\bar{c}\left(q_{n}^{S S *}+q_{r}^{S S *}\right) \\
& -(1-\eta) c_{L} \tau_{S}^{S S * 2}
\end{aligned}
$$

subject to $\phi_{1} \leq q_{n}^{S S *}, \phi_{2} \leq q_{r}^{S S *}$

The supplier's profit expression is as follows:

$$
\max \Pi_{S}^{M C *}=\left(p_{1}^{S S *}-c_{S}\right) q_{n}^{S S *}+p_{2}^{S S *} q_{r}^{S S *}-\eta c_{L} \tau_{S}^{S S *^{2}}
$$

Theorem 4. The profit function of the manufacturer is concave with respect to $p_{n}^{S S}$ and $p_{r}^{S S}$. The profit expression of the supplier is concave with respect to $p_{1}^{S S}, p_{2}^{S S}$, and $\tau_{S}^{S S}$.

Then, the backward induction method is used to solve the optimal determination of chain members. For the manufacturer, $p_{1}^{S S}$ and $p_{2}^{S S}$ are known, and from the first-order conditions of optimization, $\frac{\partial \Pi_{M}^{S S}}{\partial p_{n}^{S S}}=0$, and $\frac{\partial \Pi_{M}^{S S}}{\partial p_{r}^{S S}}=0$. The optimal solutions can be obtained.

$$
\begin{gathered}
p_{n}^{S S *}=\frac{(1-\sigma) Q}{2}+\frac{1}{2} p_{1}^{S S *}-\frac{1}{2} p_{2}^{S S *} \\
p_{r}^{S S *}=\frac{\sigma p_{1}^{S S *}+p_{2}^{S S *}-(1+\sigma)\left(\Delta \tau_{S}-r-c_{m}\right)}{2}
\end{gathered}
$$


For the supplier, $p_{1}^{S S}$ and $p_{2}^{S S}$ are determined first, and from the first-order condition of optimization, $\frac{\partial \Pi_{S}^{S S}}{\partial \tau_{S}^{S S}}=0$. The optimal solution can be obtained:

$$
\tau_{S}^{S S *}=\frac{A_{2}}{\eta} p_{1}^{S S *}+\frac{A_{2}}{\eta \sigma} p_{2}^{S S *}-\frac{A_{2}}{\eta} c_{S}
$$

where $A_{2}=\frac{\Delta(1+\sigma)}{4 c_{L}(1-\sigma)}$

Given the manufacturer's pricing decisions, the supplier makes its best reaction. For the supplier, from the first-order conditions of optimization, $\frac{\partial \Pi_{S}^{S S}}{\partial p_{1}^{S S}}=0$, and $\frac{\partial \Pi_{S}^{S S}}{\partial p_{2}^{S S}}=0$. The optimal solution can be obtained:

$$
\begin{aligned}
& p_{1}^{S S *}=\frac{B_{6}+A_{6} B_{7}}{1-A_{6} A_{7}} \\
& p_{2}^{S S *}=\frac{B_{7}+A_{7} B_{6}}{1-A_{6} A_{7}}
\end{aligned}
$$

where $A_{6}=\frac{\Delta A_{2}}{\sigma\left(2 \eta-\Delta A_{2}\right)}, \quad A_{7}=\frac{\Delta \sigma A_{2}}{2 \eta \sigma-\Delta A_{2}}, \quad B_{7}=\frac{\eta \sigma^{2}(1-\sigma) Q-(1+\sigma)\left(\eta r+\eta c_{m}+\sigma \Delta A_{2} c_{s}\right)}{(1+\sigma)\left(2 \eta \sigma-\Delta A_{2}\right)}$, $B_{6}=\frac{\frac{1-\sigma}{1+\sigma} \eta Q-\eta r-\eta c_{m}+\eta c_{s}-\Delta A_{2} c_{s}}{2 \eta-\Delta A_{2}}$

Proposition 15. In Model SS, if $\Delta^{2}(1+\sigma)^{2}>8 \eta c L \sigma(1-\sigma)$, the unit price of one new component set by supplier $p_{1}^{S S}$ increases with the cost of capacity investment coefficient $r$; otherwise, $p_{1}^{S S}$ increases as the cost of capacity investment coefficient $r$ increases. Besides, there is a linear correlation between $p_{1}^{S S}$ and $r$. The proof is similar with Proposition 4.

Proposition 16. In Model SS, if $\Delta^{2}(1+\sigma)^{2}<8 \eta c L \sigma(1-\sigma)$, the unit price of the reused component set by supplier $p_{2}^{S S}$ decreases as the cost of the capacity investment coefficient $r$ increases; otherwise, $p_{2}^{S S}$ increases with the cost of the capacity investment coefficient $r$. Besides, there is a linear correlation between $p_{2}^{S S}$ and $r$. The proof is similar with Proposition 4.

Substituting the above result into the calculation, the capacity investment of manufacturing and the capacity investment of remanufacturing can be expressed as follows:

$$
k_{1}^{S S^{*}}=\frac{1}{2} Q+\frac{(\sigma+1)\left[p_{1}^{S S}+c_{m}+r+\frac{\Delta A_{2}}{\eta}\left(c_{S}-p_{1}^{S S}+\frac{p_{2}^{S S}}{\sigma}\right)\right]}{2(\sigma-1)}-\phi_{1}
$$

Furthermore, the capacity investment of remanufacturing can be expressed as:

$$
\begin{aligned}
k_{2}^{S S *} & =\frac{(\sigma+1)\left[c_{m}+r+\frac{\Delta A_{2}}{\eta}\left(c_{S}-p_{1}^{S S}+\frac{p_{2}^{S S}}{\sigma}\right)\right]+p_{2}^{S S}}{2 \sigma(\sigma-1)} \\
& +\frac{\sigma\left[p_{2}^{S S}-p_{1}^{S S}+Q(\sigma-1)\right]+\sigma p_{1}^{S S}}{2 \sigma(\sigma-1)}-\phi_{2}
\end{aligned}
$$

Proposition 17. In Model SS, we have the following:

[1] If $\Delta^{2}(1+\sigma)>T$, the manufacturer's capacity investment in manufacturing $k_{1}^{S S}$ increases with the unit price of one new component set by supplier $p_{1}^{S S}$; otherwise, $k_{1}^{S S}$ decreases as $p_{1}^{S S}$ increases; $k_{1}^{S S}$ increases with the unit price of one reused component set by supplier $p_{2}^{S S}$. Where $T=4 c_{L} \eta(1-\sigma)$.

[2] If $\Delta^{2}(1+\sigma)>\sigma T$, the amount of the manufacturer's capacity investment for remanufacturing $k_{2}^{S S}$ increases with the unit price of one reused component set by supplier $p_{2}^{M S}$; otherwise, 
$k_{2}^{S S}$ decreases as $p_{1}^{S S}$ increases; $k_{2}^{S S}$ increases with the unit price of one new component set by supplier $p_{1}^{S S}$.

The proof is similar with Proposition 5.

Then, bringing the above results back to the income function, the maximum profit of CLSC members and the maximum revenue of this CLSC are calculated.

\subsubsection{With Two-Way Contract (Scenario SD)}

In this scenario, the supplier is assumed to be the leader of the Stackelberg game, and the manufacturer is the follower. The supplier determines the best recovery rate and makes its components' pricing decision to maximize its own profit. Based on the supplier's decision, the manufacturer makes its pricing decisions. All members of the CLSC aim to maximize their own profit. Further, the collecting process is completed by the supplier in this scenario, and the supplier and the manufacturer form a double coordination contract. The supplier shares the manufacturer's capacity investment cost, while the manufacturer shares the supplier's recovery cost.

The supplier decides $p_{1}^{S D}$ and $p_{2}^{S D}$, the optimal price of two kinds of components. Then, the supplier determines the best recovery rate $\tau_{S}^{S D}$, and the manufacturer reacts and determines simultaneously the optimal price $p_{n}^{S D}$ and $p_{r}^{S D}$.

The manufacturer's profit expression is as follows:

$$
\begin{aligned}
\max \Pi_{M}^{M C *} & =\left(p_{n}^{S D *}-p_{1}^{S D *}\right) q_{n}^{S D *}+\left(p_{r}^{S D *}-p_{2}^{S D *}\right) q_{r}^{S D *}-\mu\left(r k_{1}^{S D *}+r k_{2}^{S D *}\right)-\bar{c}\left(q_{n}^{S D *}+q_{r}^{S D *}\right) \\
& -(1-\eta) c_{L} \tau_{S}^{S D * 2}
\end{aligned}
$$

subject to $\phi_{1} \leq q_{n}^{S D *}, \phi_{2} \leq q_{r}^{S D *}$

The supplier's profit expression is as follows:

$$
\max \Pi_{S}^{M C *}=\left(p_{1}^{S D *}-c_{S}\right) q_{n}^{S D *}+p_{2}^{S D *} q_{r}^{S D *}-(1-\mu)\left(r k_{1}^{S D *}+r k_{2}^{S D *}\right)-\eta c_{L} \tau_{S}^{S D * 2}
$$

Theorem 5. The profit function of the manufacturer is concave with respect to $p_{n}^{S D}$ and $p_{r}^{S D}$. The profit expression of the supplier is concave with respect to $p_{1}^{S D}, p_{2}^{S D}$, and $\tau_{S}^{S D}$.

For the manufacturer, $p_{1}^{S D}$ and $p_{2}^{S D}$ are known, and from the first-order conditions of optimization, $\frac{\partial \Pi_{M}^{S D}}{\partial p_{n}^{S D}}=0$, and $\frac{\partial \Pi_{M}^{S D}}{\partial p_{r}^{S D}}=0$. The optimal solutions can be obtained.

$$
\begin{gathered}
p_{n}^{S D *}=\frac{(1-\sigma) Q}{2}+\frac{1}{2} p_{1}^{S D *}-\frac{1}{2} p_{2}^{S D *} \\
p_{r}^{S D *}=\frac{\sigma p_{1}^{S D *}+p_{2}^{S D *}-(1+\sigma)\left(\Delta \tau_{S}-\mu r-c_{m}\right)}{2}
\end{gathered}
$$

For the supplier, $p_{1}^{S D}$ and $p_{2}^{S D}$ are determined first, and from the first-order condition of optimization, $\frac{\partial \Pi_{S}^{S D}}{\partial \tau_{S}^{S D}}=0$. The optimal solution can be obtained.

$$
\tau_{S}^{S D *}=\frac{A_{2}}{\eta}\left[p_{1}^{S S *}+\frac{p_{2}^{S S *}}{\sigma}-c_{S}-\frac{r(1+\sigma)(1-\mu)}{\sigma}\right]
$$

where $A_{2}=\frac{\Delta(1+\sigma)}{4 c_{L}(1-\sigma)}$.

Given the manufacturer's pricing decisions, the supplier makes its best reactions. The optimal solution can be obtained.

$$
p_{1}^{S D *}=\frac{A_{8}+A_{6} B_{8}}{1-A_{6} A_{7}}
$$




$$
p_{2}^{S D *}=\frac{B_{8}+A_{7} A_{8}}{1-A_{6} A_{7}}
$$

where $A_{6}=\frac{\Delta A_{2}}{\sigma\left(2 \eta-\Delta A_{2}\right)}, A_{8}=\frac{\eta \frac{1-\sigma}{1+\sigma} Q-\eta\left(\mu r+c_{m}\right)+c_{s}\left(\eta-\Delta A_{2}\right)+r(1-\mu)\left(\eta-\Delta A_{2}-\frac{\Delta A_{2}}{\sigma}\right)}{2 \eta-\Delta A_{2}}, A 7=\frac{\Delta \sigma A_{2}}{2 \eta \sigma-\Delta A_{2}}$, $B_{8}=\frac{\eta \sigma^{2} \frac{1-\sigma}{1+\sigma} Q-r(1-\mu)\left(\Delta A_{2}-\eta \sigma\right)-\Delta \sigma A_{2}\left[c_{s}+r(1-\mu)\right]-\eta \sigma\left(\mu r+c_{m}\right)}{2 \eta \sigma-\Delta A_{2}}$

Substituting the above result into the calculation, the capacity investment of manufacturing can be expressed as follows.

$$
k_{1}^{S D^{*}}=\frac{1}{2} Q+\frac{p_{1}^{S D}+\sigma p_{1}^{S D}+(\sigma+1)\left[c_{m}+\mu r+\frac{\Delta A_{2}}{\eta}\left(c_{s}-p_{1}^{S D}+\frac{p_{2}^{S D}}{\sigma}\right)\right]}{2(\sigma-1)}-\phi_{1}
$$

Furthermore, the capacity investment of remanufacturing can be expressed as:

$$
\begin{aligned}
k_{2}^{S D^{*}} & =\frac{(\sigma+1)\left[c_{m}+\mu r+\frac{\Delta A_{2}}{\eta}\left(c_{S}-p_{1}^{S D}+\frac{p_{2}^{S D}}{\sigma}\right)\right]}{2 \sigma(\sigma-1)} \\
& +\frac{p_{2}^{S D}+\sigma\left[p_{2}^{S D}-p_{1}^{S D}+Q(\sigma-1)\right]+\sigma p_{1}^{S D}}{2 \sigma(\sigma-1)}-\phi_{2}
\end{aligned}
$$

Then, bringing the above results back to the income function, the maximum profit of CLSC members and the maximum revenue of this CLSC are calculated.

\section{Numerical Examples}

In this section, based on those optimal solutions of the model calculated above, the sensitivity of some important parameters and the decision variables are analyzed. The important parameters include the consumer's market preference coefficient for remanufactured products $\sigma$ and production capacity investment cost coefficient $r$, recovery cost coefficient $c_{L}$, and cost sharing coefficient $\eta$ and $\mu$. Through numerical experiments, we compare the relationship between the optimal pricing, optimal recovery rate and maximum revenue of the members in the CLSC under different collecting modes and different coordination contract conditions. Further, the influence of different values of important parameters on each optimal decision is discussed. In addition, the best recovery method and the best coordination contract are obtained based on the experimental results.

This research uses MATLAB to carry out related numerical experiments. Based on the data given in some references [16], and combined with the above assumptions in this article and the relevant conditions of the actual system, after making appropriate adjustments, the parameter values are given as Table 2 .

Table 2. The value of the parameters.

\begin{tabular}{ccccccccccc}
\hline$Q$ & $\phi_{1}$ & $\phi_{2}$ & $c_{s}$ & $c_{m}$ & $c_{r}$ & $c_{L}$ & $r$ & $\sigma$ & $\mu$ & $\eta$ \\
\hline 50 & 1 & 1 & 1 & 0.5 & 0.1 & 20 & 0.6 & 0.6 & 0.2 & 0.2 \\
\hline
\end{tabular}

\subsection{The Influence of Market Preference Coefficient}

At present, many relevant documents have considered the market preference coefficient. On this basis, this study discusses the influence of the market's acceptance of remanufactured products on the capacity arrangements and capacity investment decisions of members in the chain. Combining the existing literature assumptions with the actual situation, this study considers the market preference coefficient of remanufactured products $\sigma \in[0.4,0.8]$. This section separately studies the relationship between the pricing of the two products, the recovery rate decision and the amount of capacity investment and market preferences. 
The numerical experiment results are shown in Figure 2a-e below. Figure 2a,b show the influence of market preference on product pricing. Figure $2 c, d$ illustrate the relationship between the amount of capacity investment and the market's preference for remanufactured products. Figure 2e shows the change trend of the recovery rate with the market preference coefficient under different models. The results show that as the market's preference for remanufactured products increases, manufacturers' prices for both products are getting lower and lower under different collecting models and coordination contracts, and the amount of production capacity investment in manufacturing activities also gradually declines. The amount of remanufacturing capacity investment responds differently to changes in market preferences under different scenarios. Capacity investment in remanufacturing activities increases and then decreases in the manufacturer collecting model, while the amount of remanufacturing capacity investment gradually decreases in the supplier collecting model. The collecting rate shows a small trend of increasing and then decreasing as the market preference for remanufactured products increases. Such a trend of change is conceivable. As the market's preference for remanufactured products increases, more consumers are willing to buy remanufactured products, and the competitiveness of new products declines, and their demand also declines. The manufacturer's original production capacity is enough to meet most of the demand, and the production capacity that requires additional investment is reduced accordingly. At this time, to cope with the loss of market share, the manufacturer decides to lower the selling price. Accordingly, remanufactured products that compete with new products must make adjustments to lower prices slightly.

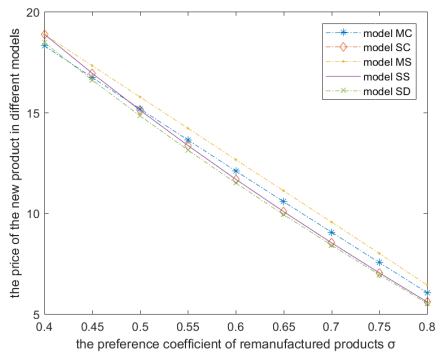

(a)

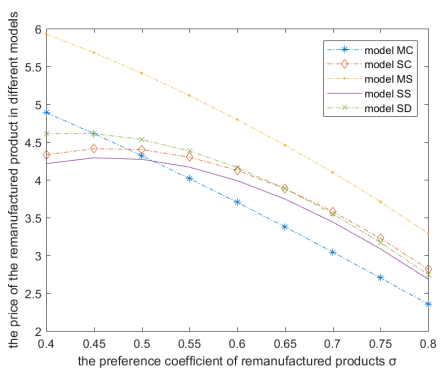

(b)

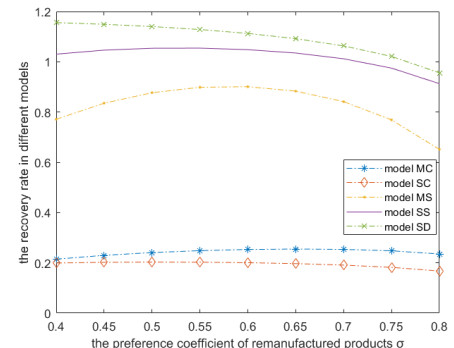

(c)

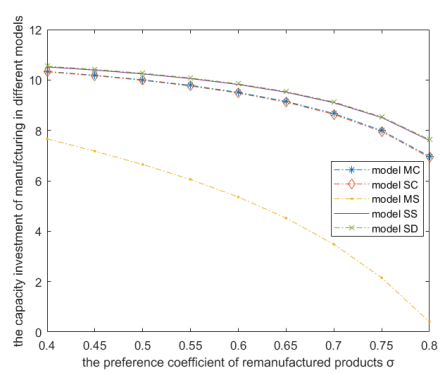

(d)

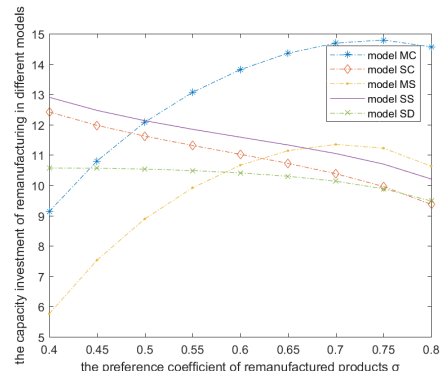

(e)

Figure 2. Sensitivity analysis of the preference coefficient of remanufactured products $\sigma$. (a) The price of the new products. (b) The price of the remanufactured products. (c) The capacity investment of manufacturing. (d) The capacity investment of remanufacturing. (e) The recovery rate.

It is worth mentioning that the difference between the numerical experiment conducted in this study and the existing literature is that the influence of the market preference coefficient on the amount of capacity investment has also been explained. In different models, the production capacity investment of new products has the same trend; and the relationship between the production capacity investment of remanufactured products and market preferences is related to the recovery mode. Under the supplier recovery model, the amount of remanufactured product capacity investment also decreases as the market 
preference increases. Under the manufacturer's collecting model, the amount of investment in remanufacturing capacity will increase and then decrease as the market preference coefficient increases. It can be seen from Figure 2e that the recovery rate is low in the model that does not consider the coordination contract, and the product recovery rate is the highest under the condition of the supplier collecting and the double coordination contract; it can be seen from Figure 2e that the recovery rate is low in the model that does not consider the coordination contract, and the product recovery rate is the highest under the condition of the supplier collecting and the double coordination contract. In addition to the supplier collecting and considering the double coordination model, the recovery rate has shown a trend of first increasing and then decreasing with the increase of the market preference coefficient. The decrease in the recovery rate directly leads to the reduction in components used for remanufacturing, meaning that the investment in production capacity has to be reduced. In general, under the mode of supplier collecting and considering double coordination, the change in remanufacturing capacity investment is the gentlest, and the recovery rate in this case is also the highest.

If the quantity of remanufactured products is regarded as the basis for judging the green sustainability of the CLSC system, it is not difficult to find based on the results of numerical experiments that when the market's preference for remanufactured products is not high, the output of remanufactured products under the supplier collecting model is the highest in the centralized scenario; when the market prefers remanufactured products over new products, the output of remanufactured products under the manufacturer collecting model is the highest. The optimal recovery rate is always the highest under the supplier's recovery and two-way coordination model. Based on the above results, this research suggests that when the market's acceptance of remanufactured products is low, decision makers can consider entrusting the collecting activities to suppliers to complete, and appropriately increase coordination contracts; when remanufactured products have similar positions to new products in the market or are even more recognized by consumers, the collecting method of manufacturer is more appropriate. In the case of large fluctuations in market preferences or unclear market preferences, it is more appropriate to adopt a supplier collecting model and consider double coordination.

\subsection{The Influence of Capacity Investment Cost Coefficient}

In the existing literature, almost no scholars consider the upper limit of capacity when discussing capacity investment. Starting from this point of innovation, this research discusses the impact of capacity investment cost coefficients on those pricing, capacity investment and allocation decisions of chain members under capacity constraints. Combining the existing literature assumptions with the actual situation, this study considers the producer capacity investment cost coefficient $r \in(0,2]$. The relationship between the pricing of two products, the recovery rate decision, the amount of capacity investment and the capacity investment cost are studied separately.

The results of the numerical experiment are shown in Figure 3a-e below, where Figure $3 a, b$ reflect the relationship between product pricing and the capacity investment coefficient. Figure 3c,d show the influence of the capacity investment coefficient on capacity investment. Figure 3e illustrates the trend of the recovery rate. As seen in the figure, as the cost per unit of capacity investment increases, the price of remanufactured products increases in all scenarios, the amount of capacity investment in both manufacturing activities decreases, and the recovery rate decreases. Obviously, under the assumptions of this study, there is a linear relationship between the above decision variables and the capacity investment coefficient. When the unit investment cost is higher, the price of remanufactured products that require an investment in capacity will decrease, and the amount of capacity investment will also decrease. It is not difficult to understand that when remanufacturing costs increase, price increases will be used to reduce losses. At this time, demand decreases, and production capacity, which requires additional investment, also decreases. In particular, as seen in Figure $3 a$, under the supplier collecting mode, 
the higher the investment cost per unit of capacity, the higher the pricing of brand new products, but under the manufacturer collecting mode, with the increase in the investment cost of unit capacity, the price of new products has decreased slightly. This means that the cost per unit of capacity investment does not have a significant impact on the price of new products when the manufacturer collects. This is consistent with the reality that manufacturers tend to invest more capacity in the manufacture of new products and do not need to invest too much additional capacity when demand is stable.

If the quantity of remanufactured products is regarded as an evaluation indicator of the sustainability of the CLSC, under the manufacturer collecting model, regardless of how high the unit cost is, no cost sharing is better than the scenario of considering cost sharing; in the supplier collecting model, it is better to consider a single cost sharing contract; in all scenarios, when the manufacturer collects and does not consider the coordination contract, the investment in remanufacturing is the largest. This is different from the general understanding, which considers that the coordination contract cannot optimize the system in all situations. Lower production capacity investment costs denote a desired objective of any manufacturer. Manufacturers can increase their versatility when initially setting up production lines, or they can find production lines with lower rental prices, which are both approaches conducive to the improvement of the manufacturers' revenue and the sustainable development of the entire supply chain.

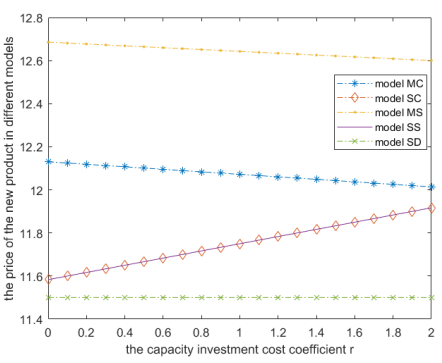

(a)

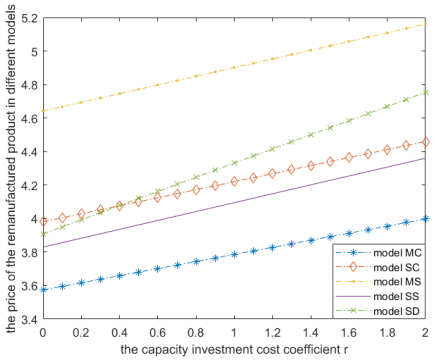

(b)

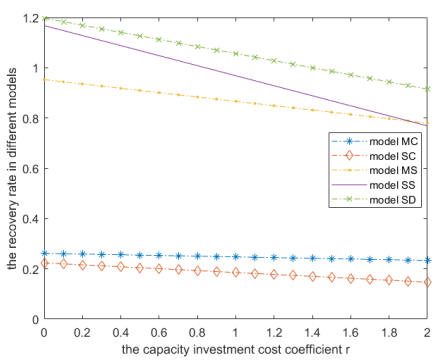

(c)

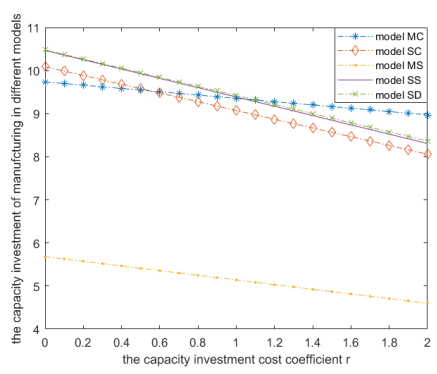

(d)

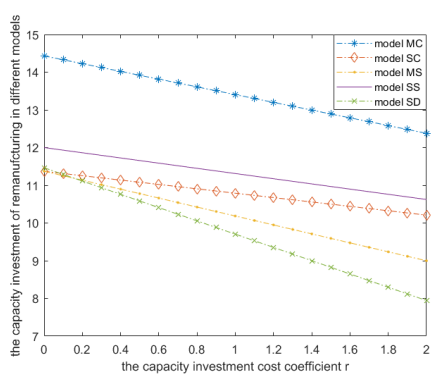

(e)

Figure 3. Sensitivity analysis of the capacity investment cost coefficient $r$. (a) The price of the new products. (b) The price of the remanufactured products. (c) The capacity investment of manufacturing. (d) The capacity investment of remanufacturing. (e) The recovery rate.

\subsection{The Influence of Cost Sharing Factor}

Cost sharing is a common method of coordination and cooperation in supply chain systems. This study discusses the impact of sharing the cost of collecting on the decisionmaking of members under two collection modes. Combining the existing literature assumptions with the actual situation, consider the cost sharing coefficient $\eta \in[0,1], \mu \in[0,1]$. We separately study the relationship between the optimal pricing of two products, the amount of capacity investment and the cost-sharing coefficient.

The results of the numerical experiment are shown in Figure $4 \mathrm{a}, \mathrm{b}$ below, it can be seen that the impact of cost-sharing ratio on the amount of capacity investment in manufacturing 
activities, remanufacturing activities, and the pricing of both products when considering the coordination contract under the two modes of manufacturer collection and supplier collection, respectively. Figure 4a shows that as the cost-sharing ratio increases, the amount of investment in both capacities increases in the manufacturer collecting mode, while the amount of investment in capacity decreases in the supplier collecting mode as the sharing ratio increases, and the amount of investment in remanufacturing capacity is always greater than the amount of investment in capacity for manufacturing activities in both modes, and the investment in new product capacity under the supplier collecting model is higher than that under the manufacturer collecting mode. As seen in Figure $4 \mathrm{~b}$, the pricing of new products is always higher than that of remanufactured products, the pricing under the supplier collecting mode is not sensitive to the cost sharing factor, and the pricing of both products decreases as the sharing factor increases when the manufacturer collects, which means that reasonable coordination can reduce the selling price of the products.

An analysis of the results of numerical experiments shows that a small cost-sharing ratio has an effective impact on the decision-making of CLSC members. When the costsharing ratio is too large, it will have little effect on decision-making. With an appropriate cost-sharing ratio, the supplier collecting model is more conducive to the sustainable development of the supply chain. Therefore, the impact of effective coordination and cooperation on product pricing and output is conducive to promoting the sustainable development of the CLSC.

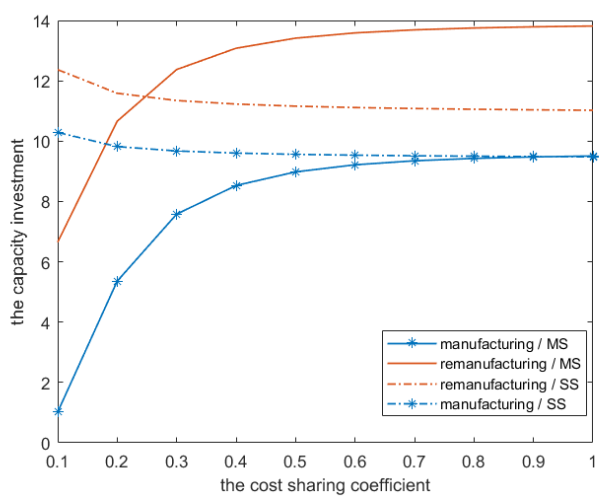

(a)

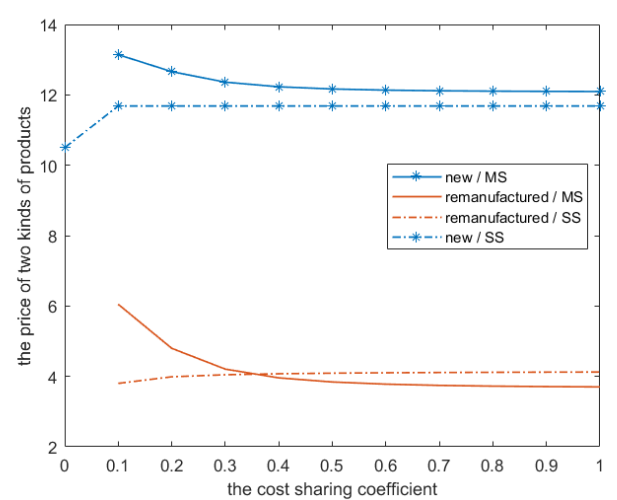

(b)

Figure 4. Sensitivity analysis of the cost sharing coefficient $\eta / \mu$. (a) The capacity investment of two kinds of products in different models. (b) The price of two kinds of products in different models.

\subsection{Revenue Comparison in Different Scenarios}

The above sections analyze several important parameters. This section starts from the chain members and the whole CLSC and to arrive at a better scenario, discusses the relationship between the CLSC members and the overall revenue of the CLSC in different scenarios.

As shown in Figure $5 \mathrm{a}-\mathrm{c}$, when the market preference for remanufactured products becomes greater, the overall revenues of the supplier, the manufacturer, and the CLSC all show a downward trend. From Figure $5 \mathrm{a}, \mathrm{b}$, it can be concluded that for the supplier, regardless of whether there is a contractual coordination relationship, the supplier collecting model has the greatest benefit; the supplier has the least benefits under the manufacturer collecting model with a cost sharing contract; the manufacturer has the greatest benefit under the manufacturer collecting model without a coordination contract, and the supplier collecting model with a double coordination contract has the least benefit. Figure $5 \mathrm{c}$ reveals that the overall CLSC revenue is the smallest under the manufacturer's recovery and costsharing contract mode, and the CLSC revenues of the other four scenarios are not much different; when the market's acceptance of remanufactured products is low, the overall revenue of the CLSC under the supplier collecting model is higher. When the market 
prefers remanufactured products, the manufacturer collecting model achieves the highest chain revenue. The two-way coordination contract is not very helpful in improving the overall revenue of the CLSC.

As shown in Figure 6a-c, when the unit capacity investment cost becomes larger, the overall revenues of the supplier, the manufacturer, and the CLSC all show a downward trend. From Figure $6 \mathrm{a}, \mathrm{b}$, it can be concluded that for the supplier, whether there is a contractual coordination relationship has little effect on its profit; the supplier has the least benefits under the manufacturer collecting model with a cost-sharing contract. The manufacturer gains the maximum profit under the manufacturer collecting model without a coordination contract, and the supplier collecting model with a cost-sharing contract has the least benefit. Figure $6 \mathrm{c}$ shows that the overall CLSC profit is the smallest under the manufacturer collecting with the cost-sharing contract model and that the chain profit will reach the highest under the manufacturer collecting without the coordination contract model.

The conclusions drawn from the comparison of the benefits of the two sets of numerical experiments are almost the same. For the supplier, the supplier collecting model is the best; for the manufacturer, the manufacturer collecting model is the best; that is, the leader of collecting will obtain higher profits. For the overall profit of the CLSC, the model without the coordination contract is better; compared with other models, the manufacturer collecting model can maximize the chain profit. In some suitable scenarios, the supplier collecting model can instead maximize the overall profit of the CLSC.

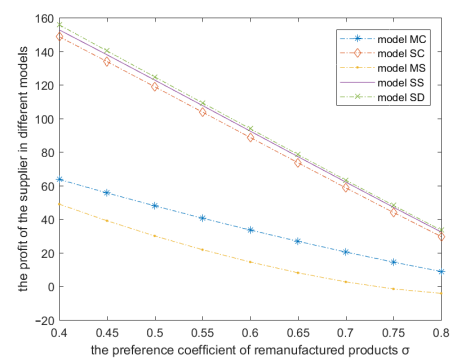

(a)

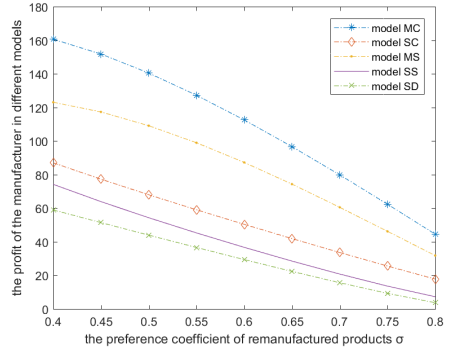

(b)

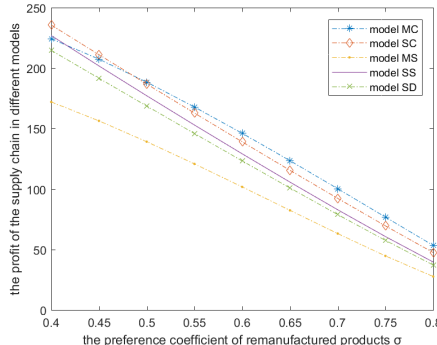

(c)

Figure 5. Sensitivity analysis of the preference coefficient of remanufactured products $\sigma$. (a) The profit of the supplier in different models. (b) The profit of the manufacturer in different models. (c) The profit of the supply chain in different models.

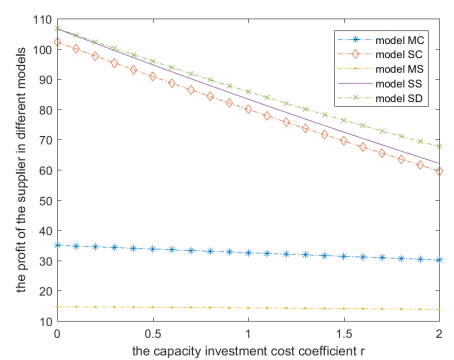

(a)

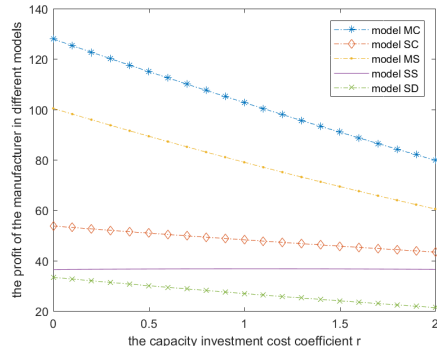

(b)

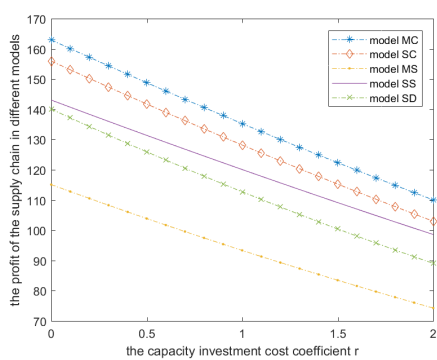

(c)

Figure 6. Sensitivity analysis of the capacity investment cost coefficient $r$. (a) The profit of the supplier in different models. (b) The profit of the manufacturer in different models. (c) The profit of the supply chain in different models.

\section{Conclusions}

Through modeling and calculation, this research has obtained the optimal decisionmaking of CLSC members in different scenarios. Based on the existing dual-collecting channel CLSC pricing problem, this paper adds the decision variable of capacity investment, considers the manufacturer's upper capacity limit, and proposes the supplier collecting channel. At the same time, a method of constructing a double coordination contract be- 
tween the manufacturer and the supplier is proposed to study the effect of the coordination contract on the CLSC decision-making problem. Through a series of numerical experiments and analysis, the corresponding conclusions are drawn and mainly include the following:

1. Experimental analyses revealed that manufacturer collecting is the optimal collecting method in most scenarios, but supplier collecting is still meaningful. In some special situations, such as when the market's acceptance of certain remanufactured products is low, the supplier collecting method can maximize the overall profit of the supply chain. The role of the supplier in the CLSC should not be limited to the supply of components for production and manufacturing, but can also be responsible for the reverse logistics activities in the CLSC. The supplier who is more familiar with components can play a greater role in the quality control of recycled products.

2. Under capacity constraints, capacity investments can generate greater returns for manufacturers and production capacity investment costs and recovery costs have a greater impact on the income of members. The lowering of production capacity investment costs is a desirable goal of any manufacturer. Manufacturers can increase versatility when initially setting the production line or can find a production line with a lower rental price. In addition, the cost of recovery affects the profitability of supply chain members and the sustainability of the chain. The collector should control collecting costs as much as possible, employing actions, such as improving collecting efficiency, reducing transportation costs in the process, and handing over collecting to a third party to complete. These approaches are conducive to the improvement of the members' income and the sustainable development of the entire supply chain.

3. A small sharing ratio has an effective impact on the decision-making of CLSC members, while excessively large cost sharing has little effect on decision-making. Different from the general understanding, the coordination contract cannot optimize the system in all situations. In some cases, it will reduce the overall profit of the CLSC. In addition, double coordination is more conducive to the leader. Therefore, for CLSC decision makers, they need to be more cautious when establishing cooperation with other companies, especially when considering cost-sharing cooperation methods. In other words, the cost-sharing method of cooperation is not worth promoting.

Some conclusions drawn from this study have some insights for enterprises. First, the market for remanufactured products is still not open. Although remanufacturing is not a new thing, some enterprises and consumers still have misconceptions about remanufacturing. Some manufacturing enterprises always think that remanufactured products will affect the market of their new products, and some consumers think that remanufactured products are second-hand products, and they do not recognize the contribution of remanufactured products to sustainable development. In the current market where the acceptance of remanufactured products is low, enterprises can consider their own components suppliers when choosing collectors, and supplier collecting at this time can bring greater benefits to enterprises. Secondly, the market demand is gradually increasing and the manufacturing capacity of enterprises is not sufficient to meet the demand. If there is no timely investment to expand their own capacity, this will lead to a reduction in the market share of enterprises, thus reducing their revenue. Timely capacity investment decision is very important. In addition, when constructing a coordination contract, firms should be careful to consider cost-sharing contracts, which can sometimes lead to lower returns; when firms act as contract dominant, they should consider two-way coordination as much as possible to obtain greater returns.

There are still many research opportunities in the future. First, this article only discusses two kinds of cooperation contracts, and the researchable cooperation contracts are much richer. Second, this article considers production constraints. However, there are also restrictions on the supply capacity of suppliers and the collection capacity of recyclers. Considering the capacity constraints of each member will bring the CLSC model closer to reality. This article takes the output of products as the criterion for judging the sustainability of CLSCs, but in reality, the measurement factors of sustainability in the 
supply chain are much more complicated. How to effectively improve the green level is a problem that requires scholars to work together to think about solutions.

Author Contributions: Conceptualization, J.W.; methodology, J.W. and W.S.; formal analysis, W.S.; writing—original draft preparation, J.W.; writing—review and editing, J.W. and W.S.; supervision, J.W.; funding acquisition, J.W. All authors have read and agreed to the published version of the manuscript.

Funding: The work described in this article was supported by National Natural Science Foundation of China (NSFC) under project No.72071084 and No.71671071. We also appreciate the anonymous reviewers for their valuable suggestions which help us a lot in improving the logic and presentation of the paper.

Data Availability Statement: Not applicable.

Conflicts of Interest: The authors declare no conflict of interest.

\section{References}

1. Appolloni, Andrea and D'Adamo, Idiano and Gastaldi, Massimo and Santibanez-Gonzalez, Ernesto DR and Settembre-Blundo, Davide Growing e-waste management risk awareness points toward new recycling scenarios: The view of the Big Four's youngest consultants. Environ. Technol. Innov. 2021, 101716, doi:10.1016/j.eti.2021.101716. [CrossRef]

2. Debo, L.G.; Toktay, L.B.; Van Wassenhove, L.N. Market segmentation and product technology selection for remanufacturable products. Manag. Sci. 2005, 51, 1193-1205. [CrossRef]

3. Lang, X.; Shi, J. The effect of capacity constraint on pricing decision and coordination contract in recycling channels. RAIRO Rech. Opér. 2021, 55, 1705.

4. Ranjbar, Y.; Sahebi, H.; Ashayeri, J.; Teymouri, A. A competitive dual recycling channel in a three-level closed loop supply chain under different power structures: Pricing and collecting decisions. J. Clean. Prod. 2020, 272, 122623. [CrossRef]

5. Ji, Y.; Yang, H.; Qu, S.; Nabe, M. Optimal Strategy for a Closed-Loop Supply Chain Considering Recycling and Warranty Channels. Arab. J. Sci. Eng. 2021, 46, 1585-1601. [CrossRef]

6. Xu, L.; Shi, J.; Chen, J. Pricing and collection rate for remanufacturing industry considering capacity constraint in recycling channels. Complexity 2020, 2020, 8391252, doi:10.1155/2020/8391252 [CrossRef]

7. Gong, Y.; Chen, M.; Zhuang, Y. Decision-making and performance analysis of closed-loop supply chain under different recycling modes and channel power structures. Sustainability 2019, 11, 6413. [CrossRef]

8. Wei, J.; Chen, W.; Liu, G. How manufacturer's integration strategies affect closed-loop supply chain performance. Int. J. Prod. Res. 2020, 1-19. doi:10.1080/00207543.2020.1762016. [CrossRef]

9. Wang, N.; He, Q.; Jiang, B. Hybrid closed-loop supply chains with competition in recycling and product markets. Int. J. Prod. Econ. 2019, 217, 246-258. [CrossRef]

10. Jain, T.; Hazra, J. Dual sourcing under suppliers' capacity investments. Int. J. Prod. Econ. 2017, 183, 103-115. [CrossRef]

11. Goyal, M.; Netessine, S. Strategic technology choice and capacity investment under demand uncertainty. Manag. Sci. 2007, 53, 192-207. [CrossRef]

12. Xiong, Y.; Zhao, Q.; Zhou, Y. Manufacturer-remanufacturing vs. supplier-remanufacturing in a closed-loop supply chain. Int. J. Prod. Econ. 2016, 176, 21-28. [CrossRef]

13. Qian, Z.; Chai, J.; Li, H.; Yan, W.; Chen, H. Implications of product upgrading confronting supplier remanufacturing. Int. J. Prod. Res. 2020, 58, 5870-5892. [CrossRef]

14. Wan, N.; Hong, D. The impacts of subsidy policies and transfer pricing policies on the closed-loop supply chain with dual collection channels. J. Clean. Prod. 2019, 224, 881-891. [CrossRef]

15. Wang, J.; Zhou, Z.; Yu, M. Pricing models in a sustainable supply chain with capacity constraint. J. Clean. Prod. 2019, 222, 57-76. [CrossRef]

16. Wang, W.; Yang, S.; Xu, L.; Yang, X. Carrot/stick mechanisms for collection responsibility sharing in multi-tier closed-loop supply chain management. Transp. Res. Part E Logist. Transp. Rev. 2019, 125, 366-387. [CrossRef]

17. Lee, D. Who Drives Green Innovation? A Game Theoretical Analysis of a Closed-Loop Supply Chain under Different Power Structures. Int. J. Environ. Res. Public Health 2020, 17, 2274. [CrossRef]

18. Li, H.; Wang, C.; Shang, M.; Ou, W.; Qin, X. Cooperative decision in a closed-loop supply chain considering carbon emission reduction and low-carbon promotion. Environ. Prog. 2019, 38, 143-153. [CrossRef]

19. Zheng, X.X.; Liu, Z.; Li, K.W.; Huang, J.; Chen, J. Cooperative game approaches to coordinating a three-echelon closed-loop supply chain with fairness concerns. Int. J. Prod. Econ. 2019, 212, 92-110. [CrossRef]

20. Wen, D.; Xiao, T.; Dastani, M. Pricing and collection rate decisions in a closed-loop supply chain considering consumers' environmental responsibility. J. Clean. Prod. 2020, 262, 121272. [CrossRef]

21. Mondal, C.; Giri, B.C. Pricing and used product collection strategies in a two-period closed-loop supply chain under greening level and effort dependent demand. J. Clean. Prod. 2020, 265, 121335. [CrossRef] 
22. Nian, Z.; Bin, L.; Kun, W.; Mengxue, W. Game Models for Closed-Supply Chain with Different Competition-Cooperation Relationships under Fairness Preference. Complexity 2020, 2020, 6793216, doi:10.1155/2020/6793216 [CrossRef]

23. Wan, N. The impacts of low carbon subsidy, collection mode, and power structure on a closed-loop supply chain. J. Renew. Sustain. Energy 2018, 10, 065904. [CrossRef]

24. Wang, J.; Zhang, T.; Fan, X. Reverse channel design with a dominant retailer and upstream competition in emerging markets: Retailer- or manufacturer- collection? Transp. Res. Part E Logist. Transp. Rev. 2020, 137, 101924. [CrossRef]

25. Wu, J.; Jiang, F.; He, Y. Pricing and horizontal information sharing in a supply chain with capacity constraint. Oper. Res. Lett. 2018, 46, 402-408. [CrossRef]

26. Hsieh, C.; Lai, H.H. Capacity allocation with differentiated product demands under dual sourcing. Int. J. Prod. Econ. 2017, 193, 757-769. [CrossRef]

27. Atamer, B.; Bakal, I.S.; Bayindir, Z.P. Optimal pricing and production decisions in utilizing reusable containers. Int. J. Prod. Econ. 2013, 143, 222-232. [CrossRef]

28. Xiang, Z.; Xu, M. Dynamic cooperation strategies of the closed-loop supply chain involving the internet service platform. J. Clean. Prod. 2019, 220, 1180-1193. [CrossRef]

29. Li, Q.; Shi, M.; Huang, Y. A Dynamic Price Game Model in a Low-Carbon, Closed-Loop Supply Chain Considering Return Rates and Fairness Concern Behaviors. Int. J. Environ. Res. Public Health 2019, 16, 1978. [CrossRef]

30. Zheng, X.; Li, D.; Liu, Z.; Jia, F.; Sheu, J.B. Coordinating a closed-loop supply chain with fairness concerns through variableweighted Shapley values. Transp. Res. Part E Logist. Transp. Rev. 2019, 126, 227-253. [CrossRef]

31. Zou, H.; Qin, J.; Yang, P.; Dai, B. A coordinated revenue-sharing model for a sustainable closed-loop supply chain. Sustainability 2018, 10, 3198. [CrossRef]

32. Yuan, Y.; Yang, J.; Li, Y.; Li, W. Necessary conditions for coordination of dual-channel closed-loop supply chain. Technol. Forecast. Soc. Chang. 2020, 151, 119823. [CrossRef]

33. Xie, J.; Zhang, W.; Liang, L.; Xia, Y.; Yin, J.; Yang, G. The revenue and cost sharing contract of pricing and servicing policies in a dual-channel closed-loop supply chain. J. Clean. Prod. 2018, 191, 361-383. [CrossRef]

34. Xie, L.; Han, H. Capacity sharing and capacity investment of environment-friendly manufacturing: Strategy selection and performance analysis. Int. J. Environ. Res. Public Health 2020, 17, 5790. [CrossRef] [PubMed] 